\title{
AGR-2 Data Qualification Report for ATR Cycle 154B
}

Binh T. Pham Jeffrey J. Einerson

The INL is a

U.S. Department of Energy National Laboratory operated by

Battelle Energy Alliance

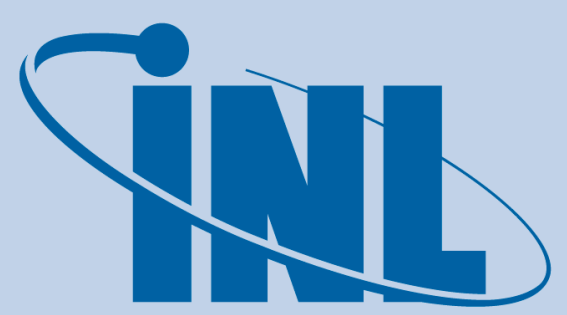

Idaho National Laboratory
January 2014

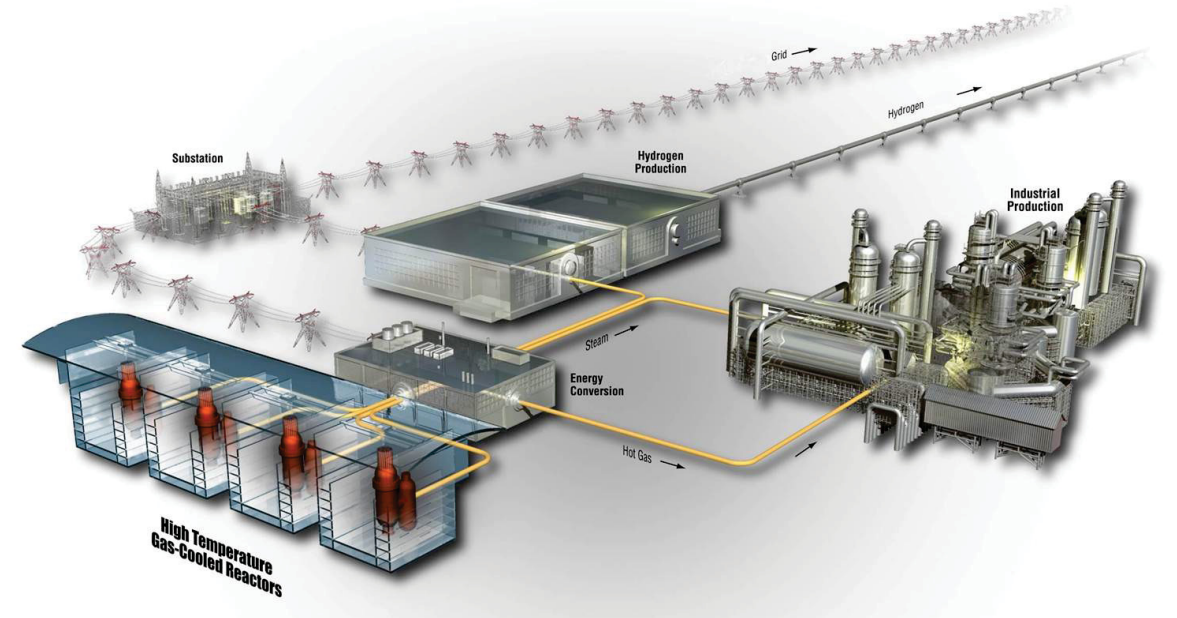




\section{DISCLAIMER}

This information was prepared as an account of work sponsored by an agency of the U.S. Government. Neither the U.S. Government nor any agency thereof, nor any of their employees, makes any warranty, expressed or implied, or assumes any legal liability or responsibility for the accuracy, completeness, or usefulness, of any information, apparatus, product, or process disclosed, or represents that its use would not infringe privately owned rights. References herein to any specific commercial product, process, or service by trade name, trade mark, manufacturer, or otherwise, does not necessarily constitute or imply its endorsement, recommendation, or favoring by the U.S. Government or any agency thereof. The views and opinions of authors expressed herein do not necessarily state or reflect those of the U.S. Government or any agency thereof. 
INL/EXT-13-30750

\title{
AGR-2 Data Qualification Report for ATR Cycle 154B
}

\author{
Binh T. Pham \\ Jeffrey J. Einerson
}

January 2014

\begin{abstract}
Idaho National Laboratory
Very High Temperature Reactor Technology Development Office Idaho Falls, Idaho 83415
\end{abstract}

http://www.inl.gov

Prepared for the

U.S. Department of Energy

Office of Nuclear Energy

Under DOE Idaho Operations Office

Contract DE-AC07-05ID14517 
Very High Temperature Reactor Technology Development Office

\title{
AGR-2 Data Qualification Report for ATR Cycle 154B
}

\author{
INL/EXT-13-30750
}

January 2014

Approved by:

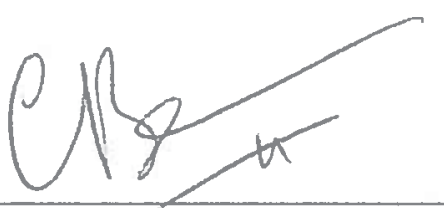

Binh T. Pham

Author

$+$

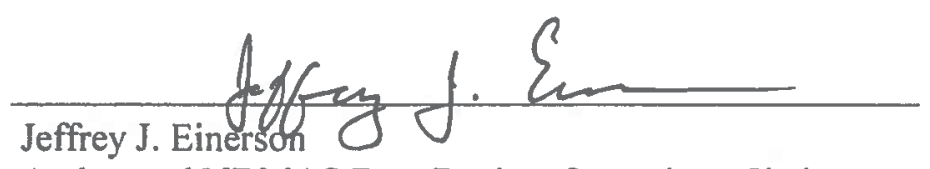

Author and NDMAS Data Review Committee Chairman

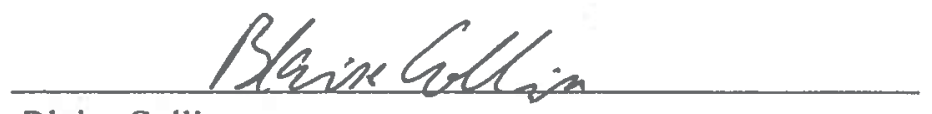

Blaise Collin

Independent Technical Reviewer

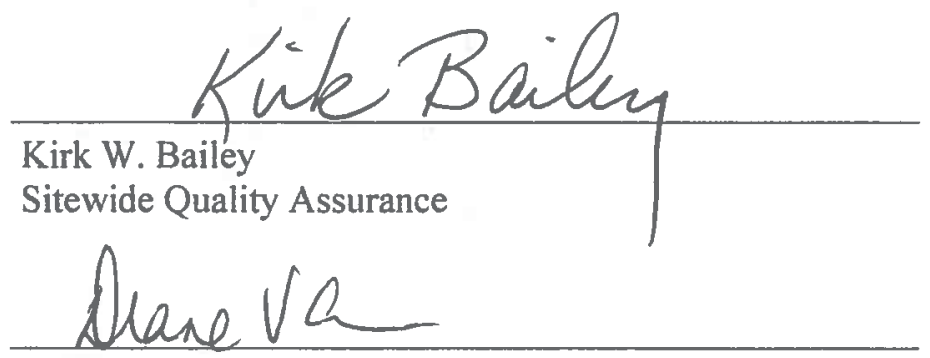

Diane V. Croson

$\frac{1-8-2014}{\text { Date }}$

VHTR TDO Deputy Director

$\frac{1-8-20 / 4}{\text { Date }}$
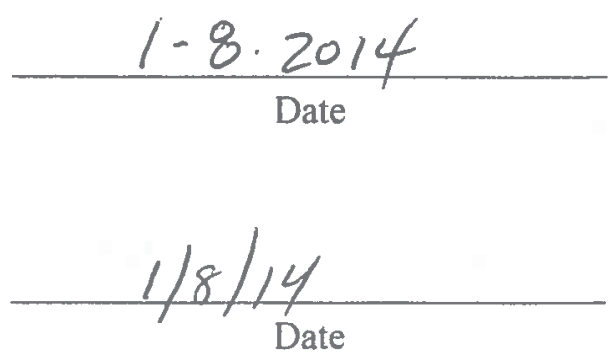


\section{SUMMARY}

This report provides the data qualification status of Advanced Gas Reactor-2 (AGR-2) fuel irradiation experimental data from Advanced Test Reactor (ATR) Cycle 154B as recorded in the Nuclear Data Management and Analysis System (NDMAS). This is the last cycle of AGR-2 irradiation, as the test train was pulled from the ATR core during the outage portion of ATR Cycle 155A. The AGR-2 data streams addressed in this report include thermocouple (TC) temperatures, sweep gas data (flow rates including new Fission Product Monitoring (FPM) downstream flows from Fission Product Monitoring System (FPMS) detectors, pressure, and moisture content), and FPMS data (release rates and release-to-birth rate ratios [R/Bs]) for each of the six capsules in the AGR-2 experiment. The final data qualification status for these data streams is determined by a Data Review Committee (DRC) comprised of AGR technical leads, Sitewide Quality Assurance (QA), and NDMAS analysts. The Data Review Committee reviewed the data acquisition process, considered whether the data met the requirements for data collection as specified in QA-approved Very High Temperature Reactor (VHTR) data collection plans, examined the results of NDMAS data testing and statistical analyses, and confirmed the qualification status of the data as given in this report.

A total of 4,986,012 instantaneous (taken every minute) TC temperature and sweep gas data records were received and processed by NDMAS for ATR Cycle 154B. Of these records, 1,774,290 (35.7\% of the total) were determined to be Failed. For temperature data records, all of the 1,774,290 records were Failed due to TC instrument failures. By end of ATR Cycle 154A, all TCs in the AGR-2 test train had failed in the following order: five TCs failed during the first four ATR cycles, 147A to 149A, (TC1/2 in Capsule 2, TC1/2 in Capsule 5, and TC5 in Capsule 6) as reported in [Abbott 2011]; four TCs failed during the next four cycles, 149B to 151B, (TC1/2 in Capsule 1 and TC1/4 in Capsule 6) as reported in [Abbott, 2012]; five TCs failed during ATR Cycles 152A to 154A (TC1/2 in Capsule 3, TC1 in Capsule 4 and TC2/3 in Capsule 6) as reported in [Pham 2013]; and the last TC, Capsule 4 TC2, failed right at the end of ATR Cycle 154A as reported in this data qualification report.

For sweep gas data, there were 3,193,722 gas flow records and of these data all 2,365,720 capsule gas flow rate records ( $\sim 74.1 \%$ of the gas flow data) were Qualified and all 828,002 FPM gas flow records ( $\sim 25.9 \%$ of the gas flow data) were Trend data due to measurement biases. Because of capsule gas cross-talk and leakage problems that occurred after ATR Cycle 150A [Abbott 2012], a procedure was implemented by AGR2 operations staff on January 17, 2012 (ATR Cycle 151A) to use an uniform neon fraction of gas mixtures in all six capsules and the leadout so the capsule's actual gas mixture can be accurately defined. Use of the capsule outlet gas flow data after ATR Cycle 150A in calculating FPMS release rate and R/B data should take into account possibilities of fission product cross-talk between capsules. The downstream flow meters help in detection of the capsule relief valves lifting.

For FPMS data, NDMAS received and processed preliminary release and R/B data for the last cycle, ATR Cycle 154B. This data consists of 12,372 release rate records and 12,372 R/B records for the 12 radionuclides reported. Due to the capsule flow cross-talk issues that began during ATR Cycle 150B, the subsequent FPMS data will not be qualified. However, the data still provide useful information for identifying particle failures and performing additional analyses and will be flagged as Trend.

All of the above data have been processed and tested using a SAS ${ }^{\circledR}$-based enterprise application software system, stored in a secure Structured Query Language database, made available on the NDMAS Web portal (http://ndmas.inl.gov), and approved by the Idaho National Laboratory (INL) Scientific and Technical Information Management System for release to both internal and external VHTR program participants. 


\section{CONTENTS}

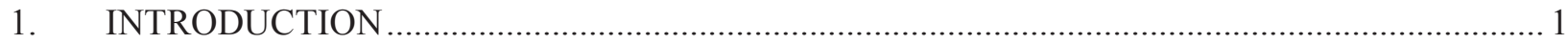

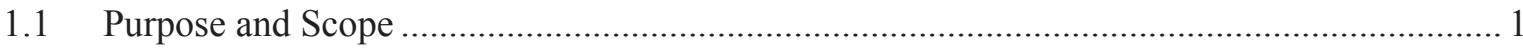

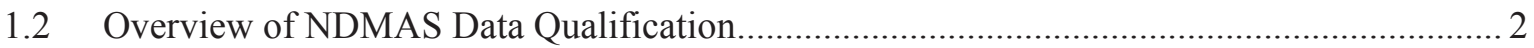

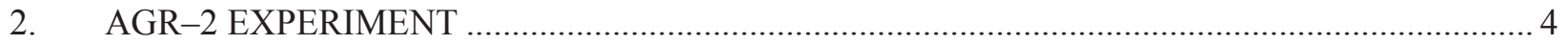

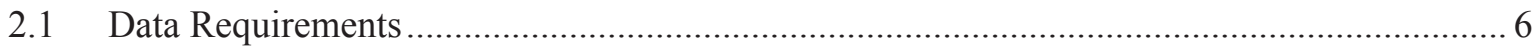

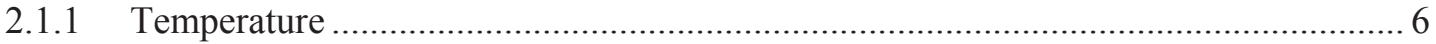

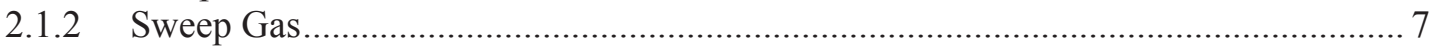

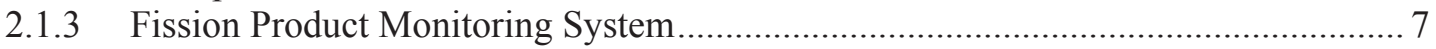

2.2 Qualification Requirements and NQA-1 Conformance ...................................................... 8

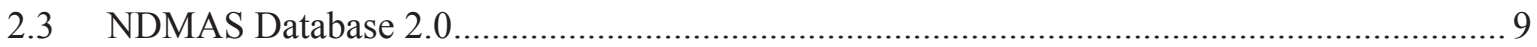

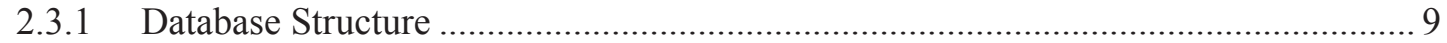

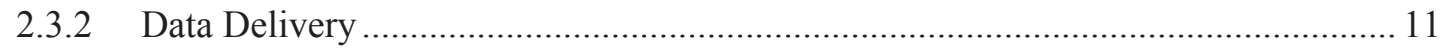

2.3.3 Irradiation Monitoring Data Capture and Testing ................................................... 11

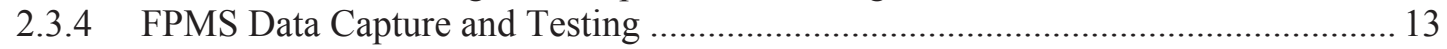

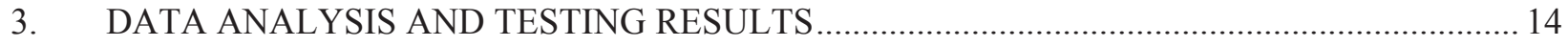

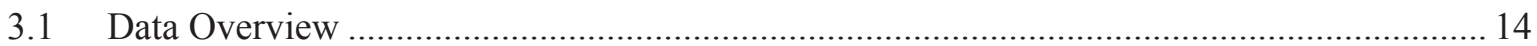

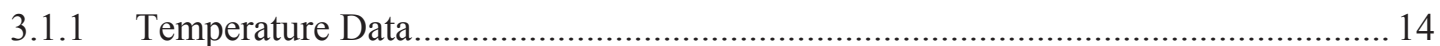

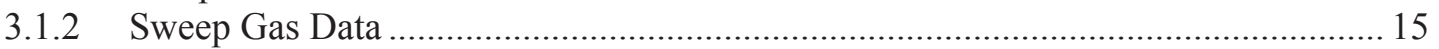

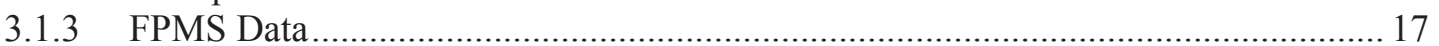

3.2 Testing for Data Anomalies of Gas Flow Rate Data.................................................... 18

3.2.1 NDMAS Capture Range Testing ..................................................................... 19

3.2.2 Testing for Failure to Maintain the Same Neon Fractions in Six Capsules

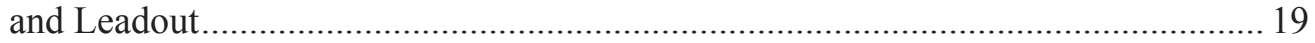

3.2.3 Downstream Gas Flow Data Failures ...................................................................... 20

3.3 Repair AGR-2 Gas Flow Data in NDMAS Database ........................................................ 22

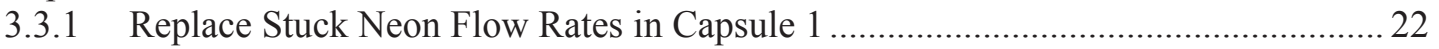

3.3.2 Replace Negative Gas Flow Rates with Zero .................................................... 23

3.3.3 Fill-in Missing Neon Flow Rates in Capsule 1 and Leadout .................................... 24

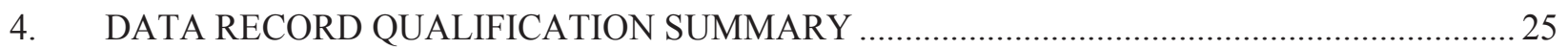

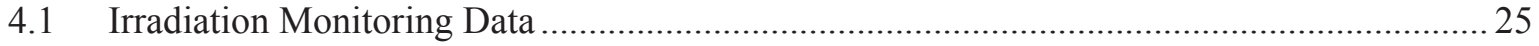

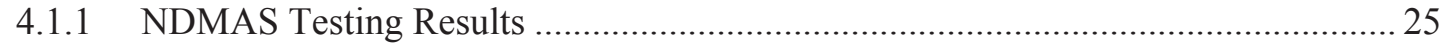

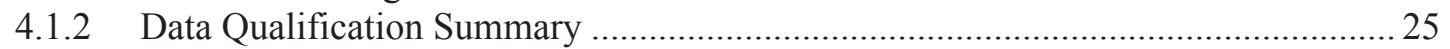

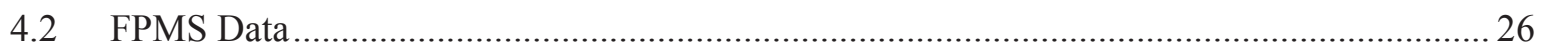

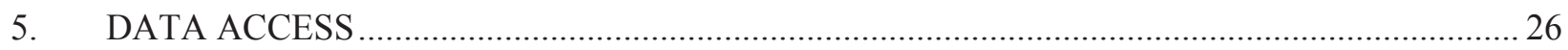

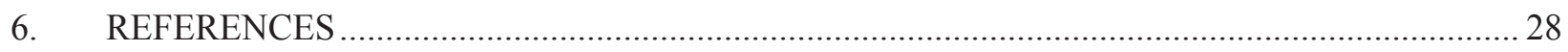

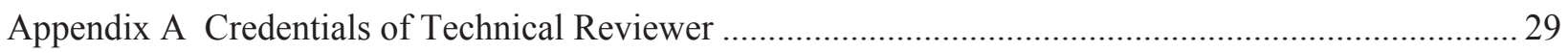




\section{FIGURES}

Figure 1. AGR-2 location in ATR core cross section. ..................................................... 4

Figure 2. Simplified flow path for AGR-2 sweep gas.................................................. 5

Figure 3. Radial (left) and axial (right) views of the AGR-2 capsules with TC locations

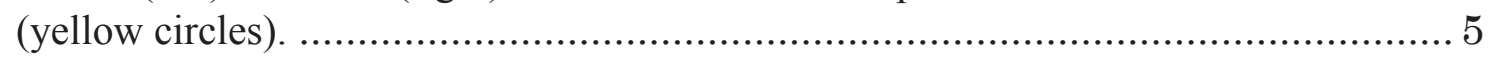

Figure 4. Data schema for time series data (Hull 2012) …................................................. 9

Figure 5. Stages of data processing within NDMAS. ....................................................... 14

Figure 6. TC2 in Capsule 4 failed on 13 July 2013 at 9:00 after it stuck at $518.754^{\circ} \mathrm{C}$ when the ATR core was powering down to zero at the end of ATR Cycle 154A........ 15

Figure 7. Capsule and leadout sweep gas flow rates $(\mathrm{sccm})$. .............................................. 16

Figure 8. Fission product release rates for $\mathrm{Kr}-85 \mathrm{~m}, \mathrm{Kr}-88$, and $\mathrm{Xe}-138$ for all AGR-2

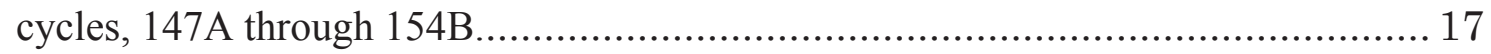

Figure 9. Fission product $\mathrm{R} / \mathrm{B}$ ratios for $\mathrm{Kr}-85 \mathrm{~m}, \mathrm{Kr}-88$, and $\mathrm{Xe}-138$ for all AGR-2 cycles

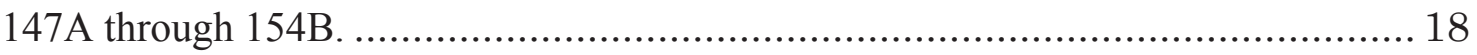

Figure 10. Capsule neon fractions for Cycle 154B ......................................................... 20

Figure 11. Downstream and outlet gas flow rates for AGR-2 U.S. capsules........................... 21

Figure 12. Capsule neon flow rates for ATR Cycles 154A and 154B showing the periods (within rectangles) when neon flow to Capsule 1 was reported erroneously due to a programming error in the automated data output script..................................... 23

Figure 13. Neon gas flow rates in AGR-2 after power-up for ATR Cycle 152B. Periods of missing gas flow data for Capsule 1 and leadout are identified with rectangles......... 24

Figure 14. The AGR-2 Web page (in blue bar on left) on the external NDMAS Web portal provides access to numerous types of data reports, graphs, and images. 


\section{TABLES}

Table 1. Fuel types in the six AGR-2 capsules (PLN-3798).................................... 6

Table 2. NDMAS data values for the AGR-2 irradiation monitoring and FPMS data............. 10

Table 4. TC Failure times for AGR-2 US capsules by the end of ATR Cycle 154A............... 13

Table 5. Overview of cycles for this reporting period.......................................... 14

Table 6. Gas flow data qualification summary for ATR Cycle 154B............................. 25

Table 7. Summary of the qualification status of the irradiation monitoring data (TC temperature and sweep gas) received by NDMAS during ATR Cycle 154B............ 26 


\section{ACRONYMS}

AGC Advanced Graphite Creep

AGR Advanced Gas Reactor

ASME American Society of Mechanical Engineers

ATR Advanced Test Reactor

CDCS Capsule Distributed Control System

CRADA Cooperative Research and Development Agreement

DRC Data Review Committee

ECAR Engineering Calculations and Analysis Report

EDMS Electronic Data Management System

EFPDs effective full power days

FPM Fission Production Monitoring

FPMS Fission Production Monitoring System

INL Idaho National Laboratory

NDMAS Nuclear Data Management and Analysis System

PALM Powered Axial Locator Mechanism

PIE post-irradiation examination

QA Quality Assurance

$\mathrm{R} / \mathrm{B} \quad$ release rate to birth rate ratio

RDAS Reactor Data Acquisition System

SQL Structured Query Language

TC thermocouple

TDO Technology Development Office

TFR Technical and Functional Requirements

TRISO tristructural isoptropic

VHTR very high temperature reactor 


\section{AGR-2 Data Qualification Report for ATR Cycle 154B}

\section{INTRODUCTION}

This report presents the data qualification status of fuel irradiation monitoring data from the Advanced Gas Reactor (AGR-2) experiment conducted in the Advanced Test Reactor (ATR) at Idaho National Laboratory (INL). AGR-2 is the second in a series of planned irradiation experiments for the AGR Fuel Development and Qualification Program, which supports development of the very high temperature reactor (VHTR) under the VHTR Technology Development Office (TDO). The experiment is intended to demonstrate the performance of tristructural isotropic (TRISO) fuel particles containing $\mathrm{UCO}$ (uranium oxycarbide) and $\mathrm{UO}_{2}$ (uranium dioxide) fuel produced in a large (6-inch) coater.

AGR-2 irradiation was first at full power on June 23, 2010 (ATR Cycle 147A) and completed irradiation when it was removed from the ATR in October 2013 (outage of ATR Cycle 155A), which resulted in 559.2 effective full power days (EFPDs) during approximately 3.5 calendar years. Qualification of data from the first nine AGR-2 cycles (ATR Cycles 147A, 148A, 148B, 149A, 149B, 150A, 150B, 151A, and 151B) was documented in [Abbott and Pham, 2011 and 2012] and qualification of data from the next five AGR-2 cycles (ATR Cycles 152A, 152B, 153A, 153B, and 154A) was documented in [Pham and Einerson, 2013]. The AGR-2 data streams addressed in this report include thermocouple (TC) temperatures, sweep gas data (flow rates including flow rates measured by the new flow meters installed downstream from Fission Product Monitoring System (FPMS) detectors (from now on these flows will be referred as FPM downstream flows), pressure, and moisture content), and FPMS data (release rates and release-to-birth rate ratios $[\mathrm{R} / \mathrm{Bs}]$ ) for each of the six capsules in the AGR-2 experiment for the last AGR-2 irradiation period, ATR cycle 154B, from July 13, 2013, through October 16, 2013.

All aspects of AGR-2 experimental data are captured and processed by the Nuclear Data Management and Analysis System (NDMAS). NDMAS processes AGR data into a secure Structured Query Language (SQL) Server database, performs testing on and analysis of the data for anomalies identification, presents the data via an access-controlled Web portal, and documents the qualification status of the data.

\subsection{Purpose and Scope}

The AGR-2 fuel irradiation monitoring data streams examined in this report include capsule TC temperatures, sweep gas measurements (gas flows, pressure, and moisture), and fission product monitoring data. The evidences of questionable data revealed by NDMAS data analysts were presented to the Data Review Committee (DRC). The DRC is comprised of project technical leads, Quality Assurance (QA), NDMAS analysts, and an independent technical reviewer (Appendix A). Final data qualification status for these data streams is determined by the DRC. The DRC considers (1) whether the data meet the requirements for data collection as specified in Test Plans, Test Specifications, Technical and Functional Requirements (TFR), and QA plans; (2) the results of data testing and statistical analyses as performed by NDMAS; (3) other QA-approved data reports submitted by data generators such as Engineering Calculations and Analysis Reports (ECARs); and (4) whether the data support applications to the defined intended use (MCP-2691, "Data Qualification"). All of the above information is summarized in this report. The final DRC findings on data qualification status are documented using FRM-1073, "Data Evaluation Report," which is stored as a record in the INL Electronic Data Management System (EDMS).

This report describes: (1) data handling procedures within NDMAS after receipt of the data from data generators; (2) NDMAS testing and statistical methods used to help identify possible data anomalies; (3) summarized information on test results and resolutions; and (4) the qualification status of the AGR-2 data records received by NDMAS during this period. 
Fuel irradiation monitoring data reported herein include the following for each of six independently controlled and monitored capsules in the AGR-2 experiment:

- TC temperatures (two in each capsule, except for Capsule 6 which has five)

- Sweep gas (helium, neon, outlet, downstream) measurements (mass flow rates, pressure, and moisture content)

- Krypton and xenon radionuclide (12 isotopes) release rates measured by the FPMS detectors and subsequently calculated krypton and xenon radionuclide R/Bs.

The basis for the qualification status of FPMS data is QA-approved ECARs submitted by the FPMS technical staff. These ECARs provide independent verification that the FPMS data submitted to NDMAS meet data collection requirements and conform to NQA-1 (ASME NQA-1-2008 with 1a 2009 addenda) requirements. However, the FPMS data during this reporting period are flagged as Trend due to the fission product cross talk between capsules as described in ECAR-2420 (Scates 2014). No similar ECARs exist for the TC and sweep gas data, so the basis for their data qualification is the DRC review of the data, data testing and analysis results, and data collection documentation as presented in this report.

This document does not address the qualification status of three additional AGR-2 data streams stored in the NDMAS database: fuel fabrication data, thermal/neutronics simulation data, and post-irradiation examination (PIE) data. All AGR-2 fuel fabrication data were qualified based on INL receipt and review of hard-copy vendor Data Certification Packages. These data have been stored in the NDMAS database and made available on the NDMAS Web portal (http://ndmas.inl.gov). AGR-2 thermal/neutronics simulation data are available up to the end of ATR Cycle 152B.Their data state is in-process and thus can be used for analysis only as preliminary data until the ECAR is issued by the modeler. AGR-2 PIE has not yet begun.

ATR operating conditions data, including lobe powers, outer shim control cylinder positions, neck shim positions, and control rod positions, are stored in the NDMAS database and presented with AGR irradiation data on the NDMAS Web portal to help experimental interpretation and to provide input for physics calculations. Because ATR data are generated outside of the VHTR TDO program, NDMAS does not formally qualify these data on a routine basis. However, to verify QA program execution for use as an NDMAS data stream, INL Sitewide QA performed an inspection of the ATR data acquisition systems and data collection processes (IAS121679 2012). This inspection confirmed implementation of the INL QA program (PDD-13000, "Quality Assurance Program Description") for the ATR data used by NDMAS in the VHTR TDO program. Additionally, NDMAS also performed several simple tests to exclude obvious failed lobe power data preventing their use in physics calculation.

\subsection{Overview of NDMAS Data Qualification}

NDMAS roles and responsibilities regarding data qualification are provided in PLN-2709, "Very High Temperature Reactor Program Data Management and Analysis Plan," and MCP-2691, "Data Qualification."

Some of the primary tasks performed by NDMAS related to data qualification are:

- Archiving submitted data in native file format on a secure $\mathrm{SAS}{ }^{\circledR}$ server under version control.

- Processing the data into standardized electronic data sets, storing the data in a secure electronic database compliant with the VHTR TDO quality assurance program plan (PLN-2690), and the records management plan (PLN-3319), and testing the data to ensure accuracy. NDMAS is currently using SAS ${ }^{\circledR}$ Enterprise Guide and a secure Microsoft SQL server (the "Vault") for these purposes.

- Analyzing irradiation monitoring data to identify possible data anomalies and trends using various SAS® statistical tools such as range testing, control charts, correlation analyses, and regression 
analyses. These results are included in data qualification reports (such as this one) that are considered by the DRC in their determination of final data Qualification State.

- Documenting the receipt of QA-approved data reports (e.g., ECARs) for FPMS and fuel fabrication data, which provide the basis for their data qualification status.

- Providing secure and appropriate Web access to the data (http://ndmas.inl.gov), information on the data qualification status, and requested data analyses to end users, including external research partners. In this instance with AGR-2, this includes secure limited data access to external research partners in France and South Africa.

All of the AGR-2 data currently being collected at INL are considered to be Type A-data obtained within an NQA-1 QA program that must meet specific requirements for data collection with independent verification that those requirements were met (MCP-2691). The final results of this process are one of three data Qualification States applied to each data record:

- Qualified. Independent verification documenting that the data meet the requirements for a specific end use as defined in a data collection plan and were collected within an NQA-1 or equivalent QA program. Any nonconformances are concluded to not affect the usability of the data.

- $\quad$ Trend. Independent verification identifying minor flaws or gaps in meeting requirements for data use. Even so, the data still provide information that can be used by the program. Data were collected within an NQA-1 or equivalent QA program. This qualification state has not been applied to any AGR-2 (or AGR-1) data to date.

- Failed. Independent verification identifies major flaws in meeting data collection requirements. Data do not provide information about the system or object. Data are not useable by the program as intended.

While the data are being processed by NDMAS and prior to the data receiving a final Qualification State, NDMAS sets the data Qualification State to In Process. Time-critical data, such as the fuel irradiation data, are made available on the NDMAS Web portal while In Process to facilitate near realtime monitoring of experimental results by project staff to improve control of the test condition predefined in the test specification plan (SPC-1064, "AGR-2 Irradiation Test Specification"). 


\section{AGR-2 EXPERIMENT}

The primary objectives of the AGR-2 experiment are defined in PLN-3636, "Technical Program Plan for the Next Generation Nuclear Plant/Advanced Gas Reactor Fuel Development and Qualification Program," and a detailed description of the experiment is provided in PLN-3798, "AGR-2 Irradiation Experiment Test Plan." The AGR-2 experiment began irradiation in the large B-12 location of the ATR core as shown in Figure 1 in June 22, 2010. AGR-2 is comprised of six individual capsules, approximately 1-3/8 in. in diameter and 6 in. long, stacked on top of each other to form the test train. A leadout tube holds the experiment in position and contains and protects the gas lines and TC wiring extending from the test train to the reactor penetration. Each capsule has independently controlled helium and neon gas flows, which have different thermal conductivities to control capsule fuel temperatures. The mixed gas outlet lines transport any fission products released from the capsules to the FPMS, which is capable of detecting individual fuel particle failures. Figure 2 shows the simplified flow path for AGR-2 sweep gas. During the "Outage" cycle, 153A, seven additional gas flow meters were installed at the outlets of the seven FPMS detectors to measure downstream gas flow rates from these detectors. Normally, gas mixture from Capsules 1- 6 flows to corresponding Detectors 1- 6 and 7 is a spare detector for replacement of a potentially failed detector. The downstream gas flow rates help determine actual flow rates through the FPMS detectors used for essential fission product release rate calculation. Ideally, the downstream flow rates are comparable to the capsule outlet flow rates measured at capsule outlets indicating tightness of the gas lines from the capsules to the FPMS detectors.

There are five TCs located in Capsule 6 and two TCs in each of the remaining capsules, as shown in Figure 3. By the end of ATR cycle 154A, all 15 installed TCs in the AGR-2 experiment failed. The last TC, TC2 in Capsule 4, failed right at the end of ATR cycle 154A as shown in this report.

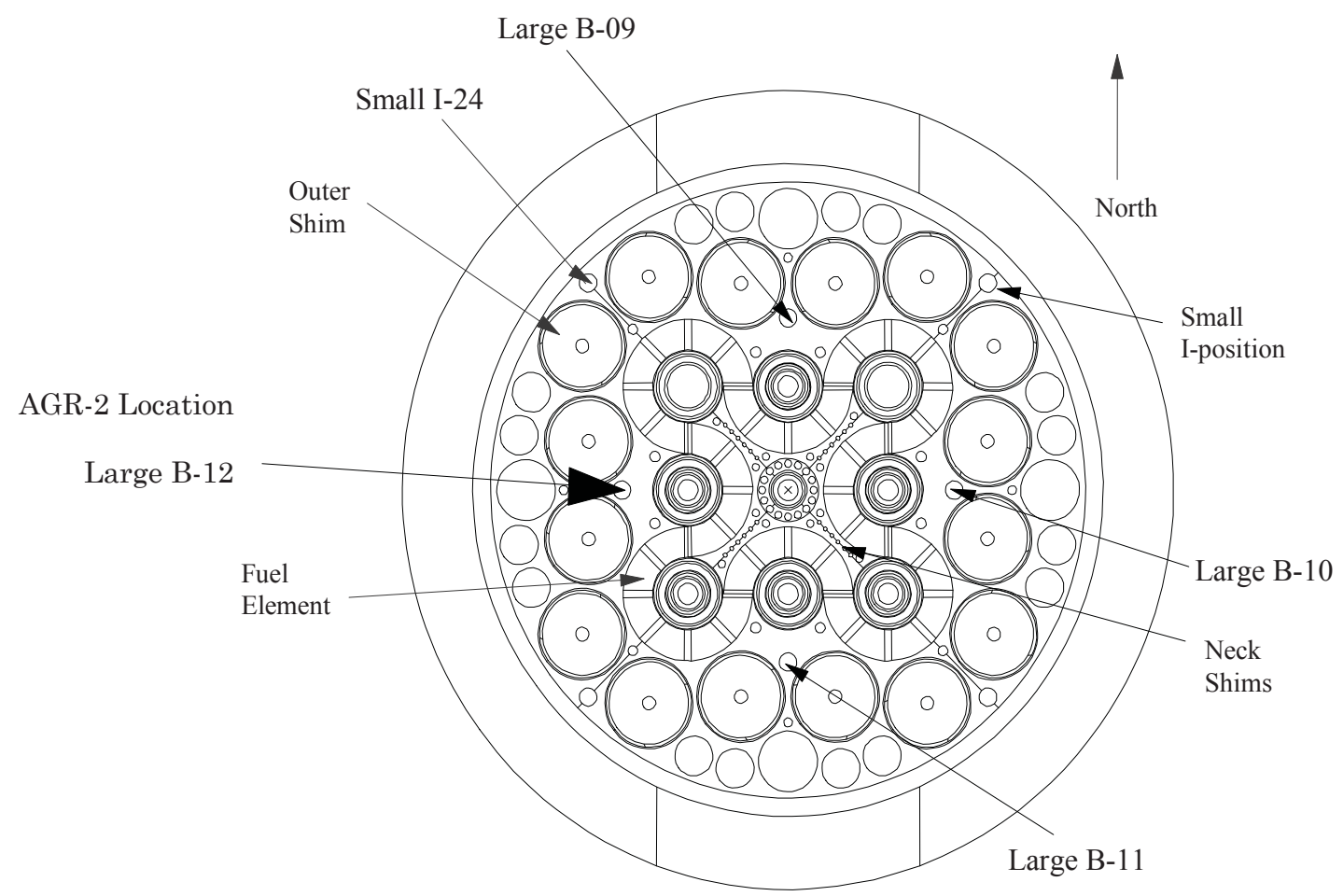

Figure 1. AGR-2 location in ATR core cross section. 


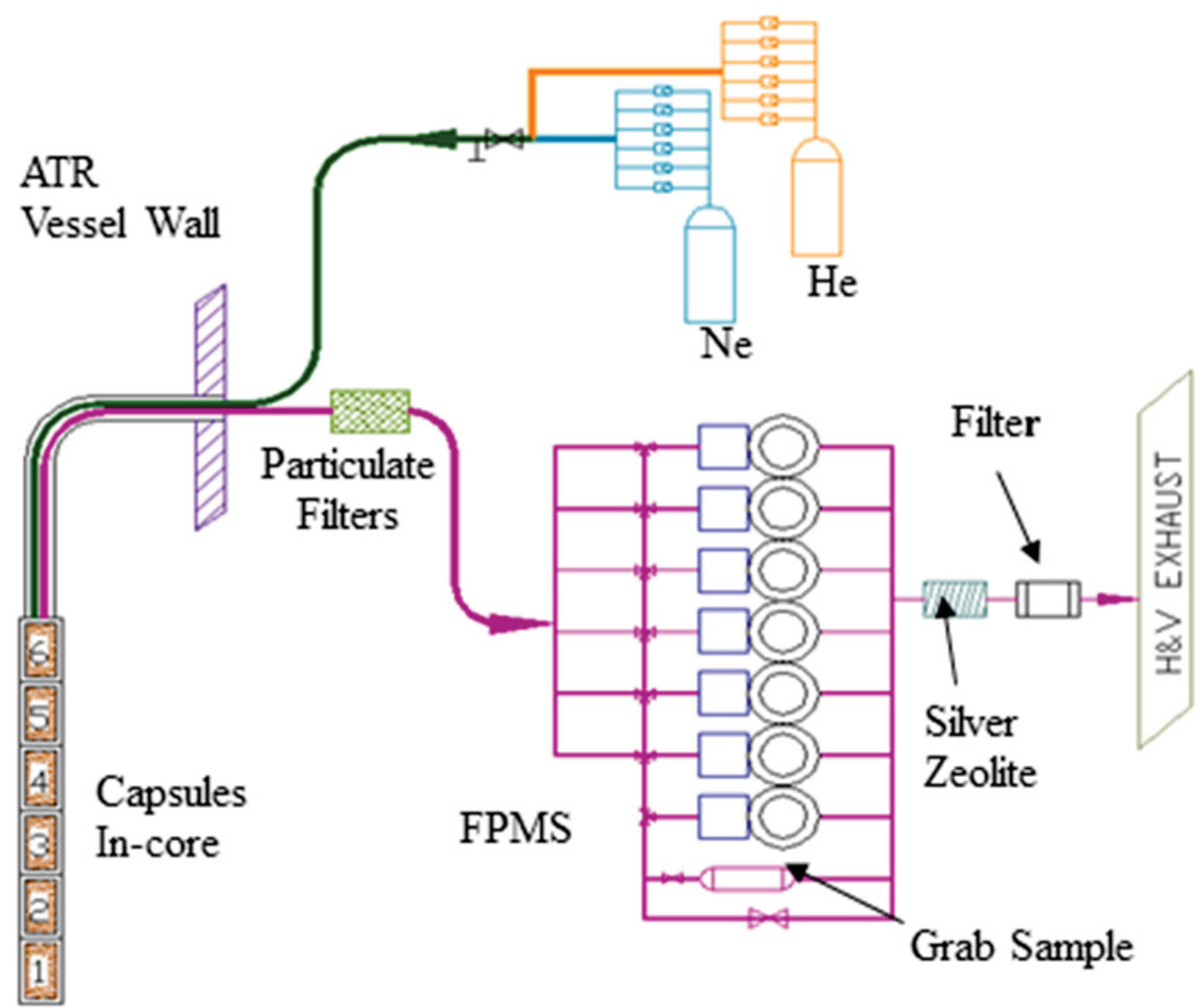

Figure 2. Simplified flow path for AGR-2 sweep gas.
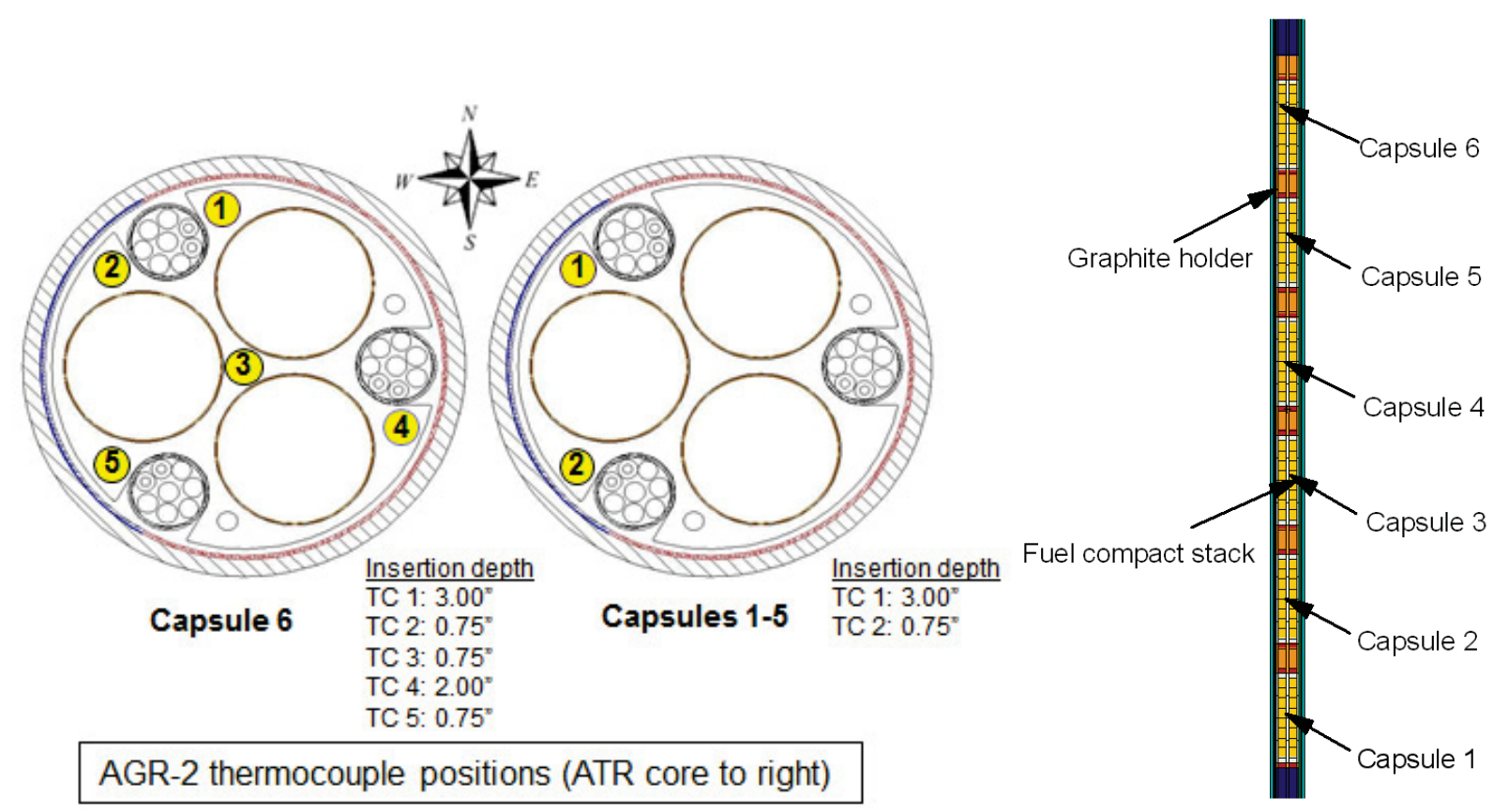

Figure 3. Radial (left) and axial (right) views of the AGR-2 capsules with TC locations (yellow circles). 
Each AGR-2 capsule contains only one fuel type. U.S. UCO fuel is in Capsules 2, 5, and 6; U.S. UO2 fuel is in Capsule 3; French $\mathrm{UO}_{2}$ fuel is in Capsule 1; and South African $\mathrm{UO}_{2}$ fuel is in Capsule 4. These assignments are listed in Table 1, where the capsules are numbered consecutively from the bottom (Capsule 1) to the top (Capsule 6). The French and South African capsule data are not presented or discussed in this report because of Cooperative Research and Development Agreement (CRADA) restrictions.

Table 1. Fuel types in the six AGR-2 capsules (PLN-3798).

\begin{tabular}{|lcl|}
\hline \multicolumn{1}{|c|}{ Location } & Coated Particle Composite & \multicolumn{1}{c|}{ Fuel Designation } \\
\hline Capsule 6 (top) & G73J-14-93073A & $\mathrm{UCO}$ \\
Capsule 5 & G73J-14-93073A & $\mathrm{UCO}$ \\
Capsule 4 & - & South African $\mathrm{UO}_{2}$ \\
Capsule 3 & G73H-10-93085B & $\mathrm{UO}_{2}$ \\
Capsule 2 & G73J-14-93073A & $\mathrm{UCO}$ \\
Capsule 1 (bottom) & - & French $\mathrm{UO}_{2}$ \\
\hline
\end{tabular}

\subsection{Data Requirements}

Requirements and specifications for the AGR-2 irradiation test are contained in TFR-559, "Requirements for the Design of the Advanced Gas Reactor Experiment AGR-2 for Irradiation in the ATR," SPC-1064, and TFR-248, "Temperature Control and Off Gas Monitoring Systems for Advanced Gas Reactor Experiment AGR-1." TFR-248 applies because the AGR-2 experiment is using the same temperature control and off-gas monitoring system as used in AGR-1. Since the start of ATR Cycle 152A, the automated feed provides to NDMAS both ATR operating data (Reactor Data Acquisition System [RDAS]) and capsule irradiation data (Capsule Distributed Control System [CDCS] for Advanced Graphite Creep [AGC] and AGR experiments) every 2 hours as described in TFR-747, "RDAS-CDCS Data Transfer to NDMAS", Revision 3.

The following requirements include only those related to the measured data provided to NDMAS during the AGR-2 experiment (TC temperatures; sweep gas flow rates, pressure, and moisture content; and FPMS data). They do not include requirements related to process or instrument parameters not reported to NDMAS (e.g., sweep gas purity), requirements specifying as-installed instrument accuracy that cannot be verified during the experiment (e.g., sweep gas flow rate accuracy of $\pm 2 \%$ ), as-installed materials specifications (e.g., hafnium shield purity), or requirements that can only be evaluated by simulation modeling or PIE activities (e.g., fast neutron fluence and burnup).

\subsubsection{Temperature}

The irradiation test condition requirements relating to fuel temperature are summarized below (SPC-1064). Fuel temperature performance can only be evaluated using thermal simulation modeling. The requirements listed below are for reference only. TC temperature data cannot be rigorously compared to these requirements because they represent graphite holder temperatures outside the fuel compacts (see Figure 3) and are instantaneous measurements every 1 minute. The fuel temperature specification listed is as follows:

- The instantaneous peak fuel temperature for each capsule shall be $\leq 1800^{\circ} \mathrm{C}$

- The time average peak fuel temperature shall be $\leq 1400^{\circ} \mathrm{C}$ for one capsule containing UCO fuel (Capsule 2), $\leq 1250^{\circ} \mathrm{C}$ for each remaining capsule containing UCO fuel (Capsules 5 and 6), and $\leq 1150^{\circ} \mathrm{C}$ for each capsule containing $\mathrm{UO}_{2}$ fuel (e.g., Capsule 3 ) 
- The time average, volume average fuel temperature goal is $\geq 1150^{\circ} \mathrm{C}$ for the highest temperature capsule containing $\mathrm{UCO}$ fuel, $\geq 1000^{\circ} \mathrm{C}$ for each remaining capsule containing $\mathrm{UCO}$ fuel, and $\geq 900^{\circ} \mathrm{C}$ for each capsule containing $\mathrm{UO}_{2}$ fuel.

\subsubsection{Sweep Gas}

The irradiation test condition requirements relating to sweep gas (helium, neon, combined outlet) are summarized as follows (SPC-1064, TFR-559, and TFR-248):

- The moisture content of inlet sweep gas on the inlet side of the capsule shall be $<5$ ppm $\mathrm{H}_{2} \mathrm{O}$, measured at least once after each gas cylinder change at a dew point of $-100 \pm 2.5^{\circ} \mathrm{C}(\mathrm{SPC}-1064$, TFR-248).

- The moisture content of the sweep gas on the outlet side of the capsule shall be measured at least every hour at a dew point of $-100 \pm 2.5^{\circ} \mathrm{C}$ and shall be indicated in volumetric water concentration in parts-per-million (ppm; SPC-1064). There is no published ppm limit or specification for moisture content on the capsule outlet side; values are monitored to ensure they do not exceed the inlet specification $(<5 \mathrm{ppm})$, which may indicate a leak (J. Maki, personal communication).

- Gas flow rates will be $\leq 50$ standard cubic centimeters per minute ( $\mathrm{sccm}$ ) at a pressure of about 15 psia or $0.103 \mathrm{MPa}(\mathrm{PLN}-3798)$.

- Test gas mixture maximum flow rate shall be between 50 and $100 \mathrm{sccm}$ (Condition 1 Normal Operations; TFR-559).

- Failure of mass flow controller or computer (Condition 2 Fault; TFR-559):

- $\quad 100 \%$ helium 0 to $100 \mathrm{sccm}$ gas flow to $100 \%$ neon 0 to $100 \mathrm{sccm}$ gas flow

- TFR-559, "Requirements for the Design of the Advanced Gas Reactor Experiment AGR-2 for Irradiation in the ATR," states, "Flow rates up to or exceeding $100 \mathrm{sccm}$ (the maximum output of the controllers) will not adversely affect the heat transfer rate from the test or invalidate the analyses."

- Failure of pressure regulator (Condition 2 Fault; TFR-559):

- $\quad 100 \%$ helium Relief Valve Setting — 90 psig

- $\quad 100 \%$ neon Relief Valve Setting_-90 psig.

\subsubsection{Fission Product Monitoring System}

The irradiation test condition requirements relating to the FPMS are as follows (SPC-1064):

- Able to detect every individual particle failure from each capsule, up to and including the first 250 failures, and able to identify in which capsule each failure has occurred (operation requirement in SPC-1064).

- Transit time of sweep gas $<25$ minutes from each capsule to the FPMS (operation requirement in SPC-1064).

- Continuous measurements of total radiation level of the sweep gas from each capsule (measurement requirement in SPC-1064).

- At least daily measurements of concentrations of at least $\mathrm{Kr}-85 \mathrm{~m}, \mathrm{Kr}-87, \mathrm{Kr}-88, \mathrm{Xe}-131 \mathrm{~m}, \mathrm{Xe}-133$, and $\mathrm{Xe}-135$ in the sweep gas from each capsule. Optional isotopes to also measure include $\mathrm{Kr}-89$, $\mathrm{Kr}-90, \mathrm{Xe}-135 \mathrm{~m}, \mathrm{Xe-137}$, Xe-138, and Xe-139 (measurement requirement in SPC-1064). 


\subsection{Qualification Requirements and NQA-1 Conformance}

All electronically recorded Type $A$ data are to be validated and qualified to confirm conformance with data collection requirements. For the irradiation monitoring data streams, this includes the following types of data for each capsule:

- TC temperatures (two TCs in each capsule, except for Capsule 6, which has five)

- Sweep gas measurements (mass flow rates [helium inlet, neon inlet, total outlet], pressure, and moisture content)

- FPMS krypton and xenon radionuclide release rates and associated error

- $\quad$ FPMS R/Bs and associated error for krypton and xenon radionuclides.

Qualified data must be collected in accordance with data collection plans that are NQA-1 compliant. Compliance of the irradiation monitoring data addressed in this report was independently verified on August 21, 2013, by a DRC comprised of AGR technical leads, INL Sitewide QA, an independent peer reviewer, and NDMAS analysts.

The data collection requirements are documented in the following QA-approved plans, procedures, specifications, and software user guides, which implement NQA-1 requirements for the VHTR TDO program:

- Program Documents

- MCP-2691, "Data Qualification"

- MCP-3058, "VHTR TDO Software Quality Assurance"

- PLN-2690, "VHTR TDO Quality Assurance Program Plan”

- $\quad$ PLN-3319, "Records Management Plan for the VHTR Technology Development Office Program"

- AGR Experiment Documents

- PLN-3636, "Technical Program Plan for the Next Generation Nuclear Plant/Advanced Gas Reactor Fuel Development and Qualification Program"

- PLN-3798, "AGR-2 Irradiation Experiment Test Plan"

- SPC-1064, "AGR-2 Irradiation Test Specification"

- TFR-248, "Temperature Control and Off Gas Monitoring Systems for Advanced Gas Reactor Experiment AGR-1", also applicable to AGR-2 experiment irradiation.

- $\quad$ TFR-559, "Requirements for the Design of the Advanced Gas Reactor Experiment AGR-2 for Irradiation in the ATR"

- TFR-747, "Technical and Functional Requirements: RDAS-CDCS Data Transfer to NDMAS"

- $\quad$ FPMS Documents (all approved by VHTR Technology Development Office and Sitewide QA quality engineer)

- GDE-503, "Users' Guide for the Fission Product Monitoring System”

- $\quad$ PLN-3551, "Fission Product Monitoring System Operability Test Plan for the AGR Experiment Series." 


\subsection{NDMAS Database 2.0}

As the number of data records and their complexity grows, the new data structure in the Vault was implemented in the NDMAS database version 2.0 (Hull 2012) applying the best practiced database technology. This structure allows storing a large amount of data and all aspects of associated information (Meta data) for reduced storage space. The systematic table structure in this relational database also speeds up the retrieval of a large amount of data via the predefined views in the Vault. This section explains the data flow to NDMAS and describes data specific to the AGR-2 irradiation experiment.

\subsubsection{Database Structure}

The new design of the NDMAS relational database is described in detail in (Hull 2012). The data storage structure is based on a hierarchy of:

$$
\text { Project } \rightarrow \text { Experiment } \rightarrow \text { Data stream } \rightarrow \text { Data package } \rightarrow \text { Data value }
$$

AGR-2 Experiment belongs to AGR project within the VHTR TDO program. A Data stream is particular work flow pathway along with related data flow into NDMAS. A Data package is a batch of data provided to NDMAS from the data generator. The number of data packages ranges from one to dozens, depending on the data stream. A data value is a single variable value recorded that provides information about the system or object being measured. Data values include response elements, usually numeric values that describe the response of the object or system (e.g., pressure or temperature) and attribute elements that generally describe the object or system being measured, or provide categorical or spatial information about the object such as thermocouple composition, graphite grade, or capsule position. When applicable (e.g., NQA-1 requirements for AGR experiments data) each data value also includes data state and qualification state representing data quality. Figure 4 shows general data schema for time series data adopted for the NDMAS database design.

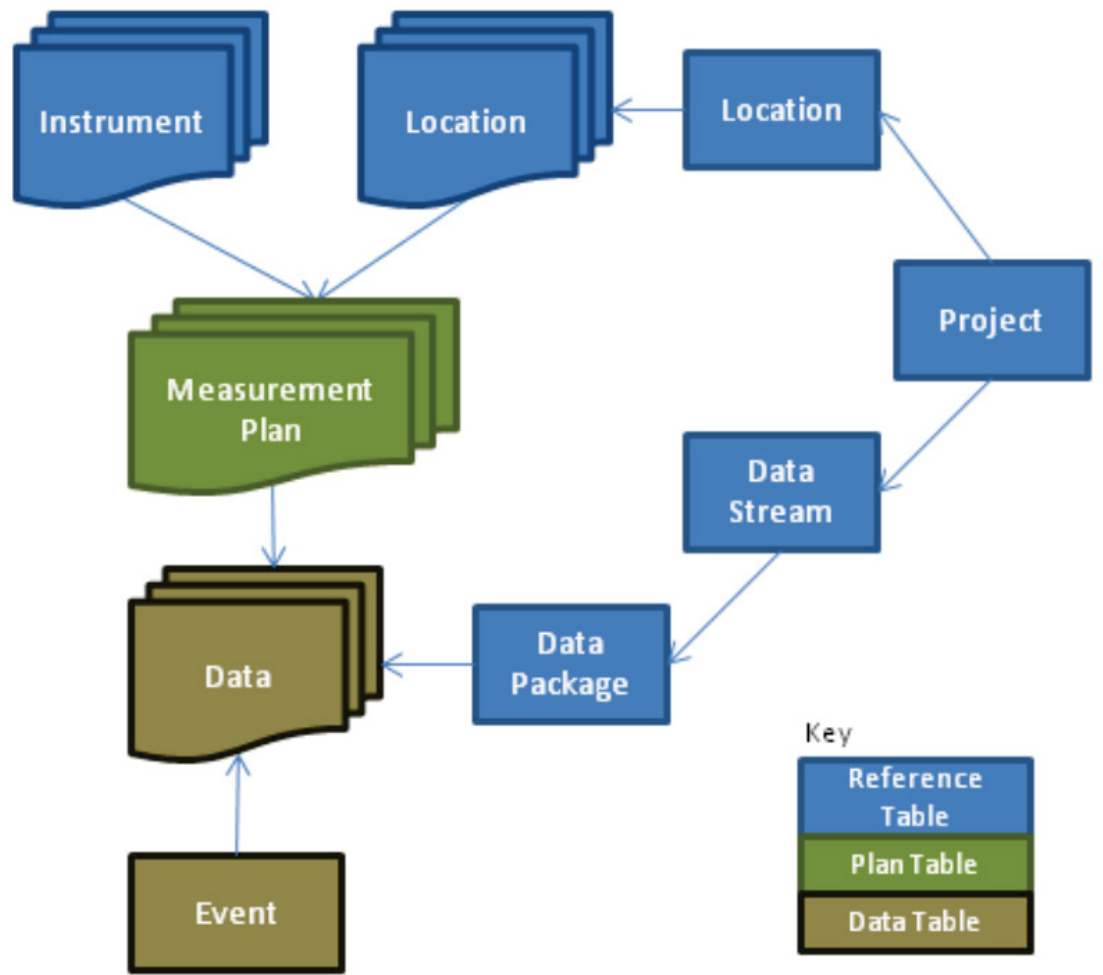

Figure 4. Data schema for time series data (Hull 2012) 
AGR-2 experiment has two time series data streams: irradiation monitoring and FPMS. The data variables stored for the AGR-2 irradiation monitoring data streams are listed in Table 2. To pull necessary information associated with a data value from various tables for data users (e.g., data analysts), numerous SQL views were created in the database. A view is an SQL query used to store data IDs to link a data value with all associated attributes from all supporting tables. For example, each temperature response in the database will be connected with its metadata such as TC description and capsule location as well as data state and qualification state. This data structure allows pulling the data state and qualification state individually for each measured temperature value as required (Hull 2012).

Table 2. NDMAS data values for the AGR-2 irradiation monitoring and FPMS data.

\begin{tabular}{|c|c|c|}
\hline \multirow{2}{*}{$\begin{array}{c}\text { Response Element } \\
\text { Response Plan Name } \\
\end{array}$} & \multicolumn{2}{|r|}{ Attribute Element } \\
\hline & Component Name & Response Description \\
\hline \multicolumn{3}{|c|}{ Irradiation Monitoring: } \\
\hline TC-1-x & AGR2_C1_TC[1,2] & TC1, TC2 Temperature in Capsule $1\left({ }^{\circ} \mathrm{C}\right)[\mathrm{x}=1,2]$ \\
\hline TC-2-x & AGR2_C2_TC $[1,2]$ & TC1, TC2 Temperature in Capsule $2\left({ }^{\circ} \mathrm{C}\right)$ \\
\hline TC-3-x & AGR2_C3_TC $[1,2]$ & TC1, TC2 Temperature in Capsule $3\left({ }^{\circ} \mathrm{C}\right)$ \\
\hline TC-4-x & AGR2_C4_TC $[1,2]$ & TC1, TC2 Temperature in Capsule $4\left({ }^{\circ} \mathrm{C}\right)$ \\
\hline TC-5-x & AGR2_C5_TC[1,2] & TC1, TC2 Temperature in Capsule $5\left({ }^{\circ} \mathrm{C}\right)$ \\
\hline TC-6-x & AGR2_C6_TC[1-5] & TC1-TC5 Temperature in Capsule $6\left({ }^{\circ} \mathrm{C}\right)[\mathrm{x}=1-5]$ \\
\hline Cxx_out_MI & AGR2_C $[01-06, \mathrm{LO}]$ & $\begin{array}{l}\text { Humidity in Capsules } 1-6 \text { and leadout gas flow (ppmv) } \\
{[\mathrm{xx}=01-06, \mathrm{LO}]}\end{array}$ \\
\hline Cxx_in_PI & AGR2_C $[01-06, \mathrm{LO}]$ & Pressure in Capsules 1-6 and leadout gas flow (psia) \\
\hline Cxx_in_Q_He & AGR2_C $[01-06, \mathrm{LO}]$ & Helium flow to Capsules $1-6$ and leadout (sccm) \\
\hline $\mathrm{Cxx}$ in_Q_ $\mathrm{Ne}$ & AGR2_C $[01-06, \mathrm{LO}]$ & Neon gas flow to Capsules $1-6$ and leadout (sccm) \\
\hline Cxx_out_Q_Total & AGR2_C[01-06] & Gas outflow from Capsules $1-6(\mathrm{sccm})[\mathrm{xx}=01-06]$ \\
\hline GSpecxx_QTotal_out & AGR2_G[01-07*] & $\begin{array}{l}\text { Gas outflow from Detectors } 1-6(\mathrm{sccm})\left[\mathrm{xx}=01-07^{*}\right] \\
* 07 \text { is a spare detector. }\end{array}$ \\
\hline \multicolumn{3}{|l|}{ FPMS: } \\
\hline $\mathrm{Kr}[\mathrm{A}] \_\mathrm{Rel}$ & AGR2 Capsule [1-6] & $\begin{array}{l}\text { Release rate for five krypton isotopes (atoms } / \mathrm{s}) \\
(\mathrm{A}=85 \mathrm{~m}, 87,88,89,90) \text { for each capsule }\end{array}$ \\
\hline $\mathrm{Kr}[\mathrm{A}] \_\mathrm{Rat}$ & AGR2 Capsule [1-6] & $\mathrm{R} / \mathrm{B}$ for five krypton isotopes (unitless) \\
\hline $\mathrm{Xe}$ [A] $]$ Rel & AGR2 Capsule [1-6] & $\begin{array}{l}\text { Release rate for seven xenon isotopes (atoms/s) } \\
(\mathrm{A}=131 \mathrm{~m}, 133,135,135 \mathrm{~m}, 137,138,139)\end{array}$ \\
\hline $\mathrm{Xe}$ [A] $]$ Rat & AGR2 Capsule [1-6] & $\mathrm{R} / \mathrm{B}$ for seven xenon isotopes (unitless) \\
\hline $\mathrm{Kr}[\mathrm{A}] \_\mathrm{Err}$ & AGR2 Capsule [1-6] & Release rate error for five krypton isotopes (\%) \\
\hline $\mathrm{Kr} \_[\mathrm{A}] \_\mathrm{REr}$ & AGR2 Capsule [1-6] & $\mathrm{R} / \mathrm{B}$ error for five krypton isotopes $(\%)$ \\
\hline $\mathrm{Xe}[\mathrm{A}] \_$Err & AGR2 Capsule [1-6] & Release rate error for seven xenon isotopes (\%) \\
\hline $\mathrm{Xe}[\mathrm{A}] \_\mathrm{REr}$ & AGR2 Capsule [1-6] & $\mathrm{R} / \mathrm{B}$ error for seven xenon isotopes $(\%)$ \\
\hline
\end{tabular}




\subsubsection{Data Delivery}

For NDMAS to reach its maximum utility in support of the temperature control of experiments, ATR operating data (RDAS) and irradiation monitoring data (CDCS) are delivered to NDMAS automatically and in near real-time every 2 hours in a readily accessible .csc format starting with ATR Cycle 152A in May 2012. Each batch of data received is a text file either from RDAS (e.g., 2013-03-19-05-13.csc) containing ATR operating condition data or from CDCS (e.g., 2013-03-19-10_cap.csc) containing irradiation monitoring data for both AGR and AGC current experiments. The automatic data transfer includes instantaneous values at 1 minute intervals for the following AGR-2 irradiation monitoring data:

- $\quad$ TC temperatures (tag name, AGR1TIxy $[\mathrm{x}=$ capsule number, $\mathrm{y}=\mathrm{TC}$ number in that capsule $]$ )

- Outlet flow (tag name, AGR1FIOUTx)

- Downstream flow (tag name, AGR1FIFPMx)

- Neon flow rate (tag name, ITVNE1FINESHF1x)

- Helium flow rate (tag name, ITVHE1FINESHF1x)

- Inlet pressure (tag name, AGR1PIINx)

- Outlet moisture (tag name, AGR1MIOUTx).

FPMS release rate and R/B data are currently provided by FPMS technical staff to NDMAS at the end of each reactor cycle. Six capsule-specific release rate and six R/B text (.csv) files are placed in the NDMAS data archive location with subversion configuration control. Data are generally provided as 8-hour averages. The first three columns of data contain SPEC_ID (sample name containing the detector number, date/time, and instrument reset index), date, and time. Columns 4 and 5 contain parameters used by the FPMS technical staff to calculate radionuclide concentrations. The remaining 24 columns contain the release rates (or R/B values) and percent error for the 12 gaseous fission products.

\subsubsection{Irradiation Monitoring Data Capture and Testing}

Upon automatic data transfer from the ATR servers, these raw data files are automatically processed into the NDMAS database by the following steps:

1. Extract data according to the tags described in TFR-747

2. Assign appropriate descriptive IDs for each response value and unique event ID for associated time stamp

3. Assign data state flag either to "Capture Passed" or "Accuracy Failed" as resulting from the initial range test and instrument failure time tests to identify any clear anomalies

4. Assign the data qualification flag to "In-process" until qualification flags are updated according to the qualification decisions from the DRC after its meeting

5. Push response value and associated integer IDs into appropriate data tables (e.g., dAGR_Temperature for TC readings) and push time stamp with unique ID into event table (e.g., dAGR_IrrEvent) into the NDMAS production database

6. Copy raw data files to NDMAS archive folder.

The automation of this data processing step uses stored procedures written in the C\# language on the .Net Application Version 1.0 framework of the Microsoft Studio 2012 development tool. All processing codes to push data to the Vault and views to pull desired data from the Vault are subject to rigorous review and testing procedures in compliance with software QA requirements described in MCP-3058 and PLN-2690. 


\subsubsection{Range Test}

Range tests evaluate whether instrument readings fall within an expected range of values, given what is known about experimental operating conditions or instrument range specifications. Range tests are used as a simple screening tool to identify data records that could potentially be bad, or they can be used to identify and reexamine extreme, but valid, data. For example, all of the TCs terminated in the graphite holders will read the graphite temperatures, which are less than the fuel compact temperature. Therefore the time average peak fuel temperature specifications given in Section 2.1.1 can be used as a "coarse" upper test limit for a TC temperature range test. Range tests are currently only applied to the TC and sweep gas (flow rates, pressure, and moisture) data that NDMAS receives. The range test limits selected for these response variables are listed in Table 3.

Table 3. Range test limits applied to AGR-2 irradiation monitoring data (see Section 2.1).

\begin{tabular}{|c|c|c|}
\hline $\begin{array}{l}\text { Response } \\
\text { Variable }\end{array}$ & $\begin{array}{l}\text { Range Test } \\
\text { Limits }^{\mathrm{a}}\end{array}$ & Comments \\
\hline $\begin{array}{l}\text { Capsule TC } \\
\text { Temperature }\end{array}$ & 0 to $1400^{\circ} \mathrm{C}$ & $\begin{array}{l}\text { Capsules } 1-6 \text {. Time average, peak fuel temperature requirement } \\
\text { for UCO fuel (SPC-1064). TC temperatures are expected to be } \\
\text { lower than this fuel temperature requirement, which can only be } \\
\text { evaluated by simulated modeling. }\end{array}$ \\
\hline $\begin{array}{l}\text { Helium/neon inlet } \\
\text { gas flow }\end{array}$ & 0 to $102 \mathrm{sccm}$ & $\begin{array}{l}\text { Capsules } 1-6 \text { and leadout. Nominal flow rates are } 0-30 \mathrm{sccm} \text {, but } \\
\text { short-term peaks in helium flow up to and exceeding } 100 \mathrm{sccm} \text { are } \\
\text { assumed to be valid (TFR-259). }\end{array}$ \\
\hline $\begin{array}{l}\text { Capsule gas } \\
\text { mixture outlet flow }\end{array}$ & 0 to $102 \mathrm{sccm}$ & Capsules 1- 6 (TFR-559). \\
\hline $\begin{array}{l}\text { Downstream gas } \\
\text { mixture flow }\end{array}$ & 0 to $102 \mathrm{sccm}$ & $\begin{array}{l}\text { Flow from } 7 \text { FPM detectors: } 1-6 \text { corresponding to } 6 \text { capsules and } 7 \\
\text { is a spare detector (TFR-747). Downstream flow rates are expected } \\
\text { to be comparable to capsule outlet flow rates. }\end{array}$ \\
\hline $\begin{array}{l}\text { Gas pressure- } \\
\text { capsule inlet }\end{array}$ & 0 to 90 psia & Capsules $1-6$ and leadout. Pressure relief valve setting (TFR-559). \\
\hline $\begin{array}{l}\text { Moisture-capsule } \\
\text { outlet }\end{array}$ & 0 to $5 \mathrm{ppm}$ & $\begin{array}{l}\text { Capsules } 1-6 \text { and leadout. No published limit for capsule outlet } \\
\text { moisture level. Limit is set to the gas inlet specification in } \\
\text { SPC-1064, the exceedance of which may indicate a leak. }\end{array}$ \\
\hline
\end{tabular}

\subsubsection{Prior Instrument Failure Time}

As the AGR-2 experiment progressed through the first 14 cycles, 14 of the 15 installed TCs in the AGR-2 experiment failed as reported in INL/EXT-11-22798, INL/EXT-12-26184, and INL/EXT-1329701. The last TC, TC2 in Capsule 4, failed when the ATR core was powering down at the end of ATR Cycle 154A. Failure times for the confirmed failed TCs are presented in Table 4 for the U.S. capsules. Readings from these TCs after the failure times can be assigned to "Accuracy Failed" data state. 
Table 4. TC Failure times for AGR-2 US capsules by the end of ATR Cycle 154A

\begin{tabular}{|c|c|l|c|}
\hline Capsule \# & $\begin{array}{c}\text { TC } \\
\text { No. }\end{array}$ & Failure Time & ATR Cycle \\
\hline 2 & 1 & 2010-11-27 16:11:00 & $148 \mathrm{~B}$ \\
\hline 2 & 2 & At fabrication & $147 \mathrm{~A}$ \\
\hline 3 & 1 & $2013-01-1810: 05: 00$ & $152 \mathrm{~B}$ \\
\hline 3 & 2 & $2013-01-1810: 05: 00$ & $152 \mathrm{~B}$ \\
\hline 5 & 1 & $2011-05-2106: 00: 00$ & $149 \mathrm{~A}$ \\
\hline 5 & 2 & $2011-05-2106: 00: 00$ & $149 \mathrm{~A}$ \\
\hline 6 & 1 & $2012-02-2911: 25: 00$ & $150 \mathrm{~B}$ \\
\hline 6 & 2 & $2013-01-1810: 05: 00$ & $152 \mathrm{~B}$ \\
\hline 6 & 3 & $2013-05-2104: 45: 00$ & $154 \mathrm{~A}$ \\
\hline 6 & 4 & $2012-03-2215: 35: 00$ & $150 \mathrm{~B}$ \\
\hline 6 & 5 & $2010-10-1220: 00: 00$ & $148 \mathrm{~A}$ \\
\hline
\end{tabular}

\subsubsection{FPMS Data Capture and Testing}

Upon receiving the FPMS data files after the end of each cycle, SAS ${ }^{\circledR}$ Enterprise Guide projects were used to capture the data from the .csv files into AGR-2 SAS ${ }^{\circledR}$ datasets. The database required description and appropriate IDs are assigned to each response value. Then, FPMS SAS data sets are pushed into four separate tables in the NDMAS database as follow: (1) date and time data inserted into "dAGR_FPMEvent" table; (2) R/B data inserted into "dAGR_FPMRatio" table; (3) release data inserted into "dAGR_FPMRelease" table; and (4) flow data inserted into "dAGR_FPMFlow" table.

For quality purposes, NDMAS does not perform any accuracy testing for FPMS data, although data analysis (e.g., regressions of R/B data with temperature) by NDMAS may be performed. Data states for FPMS records are assigned to Capture passed after matching verification between data captured to NDMAS database and raw data files. Data quality for this data stream is documented in an ECAR, which is generated by FPMS staff after each reactor cycle. When a QA-approved ECAR is received by NDMAS, a certification test is recorded in the vault for that data package, and the qualification status of the data is set to Qualified. If the FPMS data transmittal and its associated ECAR are designated as Preliminary data (as is currently the practice), it is assumed that this qualification status is subject to change if revisions to the data and revised ECARs are submitted later by the FPMS staff (as was done for AGR-1). Only the latest version of FPMS data will be used for webpage display and data download. Data from older versions are still stored in the database as Obsolete for qualification status and are available upon special request. 


\section{DATA ANALYSIS AND TESTING RESULTS}

NDMAS provides a controlled and secure electronic data storage environment, supports data qualification, identifies the qualification status of data, provides data analysis and modeling products, and makes data available for use by the program (PLN-2709). The data delivery portal (http://ndmas.inl.gov) is Web-based so both internal and external VHTR TDO program participants can access the system and review data, obtain analysis results (including statistics and graphics), and download data. By performing these roles, NDMAS assures the correct data are used by the project and data of known quality are available to support future licensing. Figure 5 summarizes the stages of data processing within NDMAS.

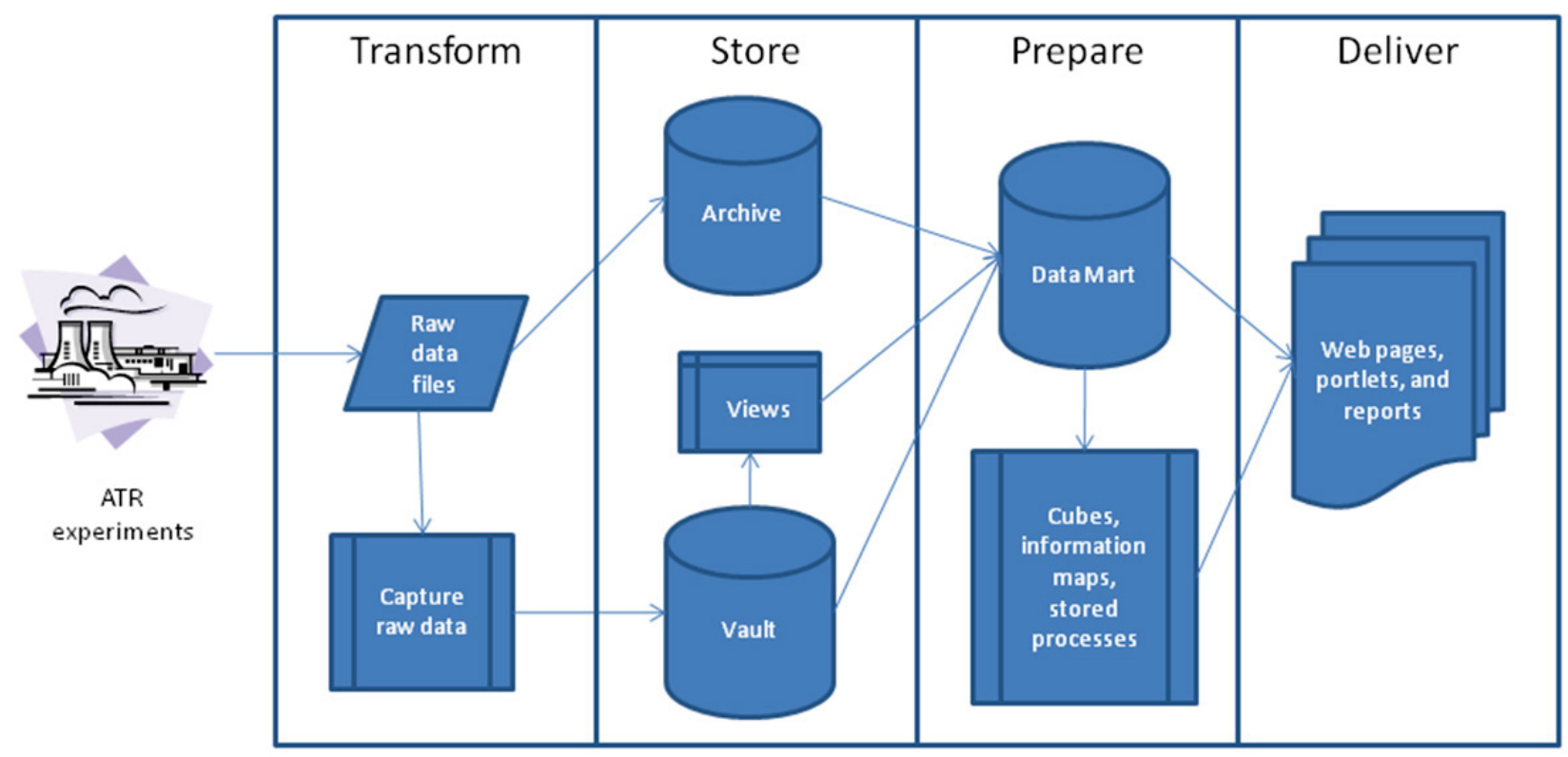

Figure 5. Stages of data processing within NDMAS.

\subsection{Data Overview}

This section provides overview plots of the AGR-2 fuel irradiation experimental data captured and processed by NDMAS for the last cycle, ATR Cycle 154B, evaluated in this report. Table 5 provides a summary of this cycle covering the period from July 13, 2013, through October 16, 2013. A total number of 4,968,012 records includes $3,193,722$ records of sweep gas flow rates $(2,365,720$ capsule flow rates and 828,002 FPM flow rates) and 1,774,290 records of TCs readings. The qualification status of these data is presented in Section 4.

Table 5. Overview of cycles for this reporting period

\begin{tabular}{|crccccc|}
\hline $\begin{array}{c}\text { ATR } \\
\text { Cycle }\end{array}$ & Record Start & Power Up & Record End & $\begin{array}{c}\text { No. of } \\
\text { EFPDs }\end{array}$ & $\begin{array}{c}\text { Total \# } \\
\text { Records }\end{array}$ & $\begin{array}{c}\text { Cycle } \\
\text { Comment }\end{array}$ \\
\hline 154B & 13JUL13:09:05 & 23AUG13:23:35 & 16OCT13:09:05 & 53.5 & $4,968,012$ & Normal \\
\hline
\end{tabular}

\subsubsection{Temperature Data}

The last operational TC in AGR-2 test train, TC2 in Capsule 4, failed right at the end of the ATR Cycle 154A as shown in Figure 6. Capsule 4 data are not qualified in this report because of CRADA restrictions, so there is no data quality discussion for TC readings during ATR Cycle 154B in this report. All TC data during this last cycle, ATR Cycle 154B, were Failed due to TC instrument failure. 


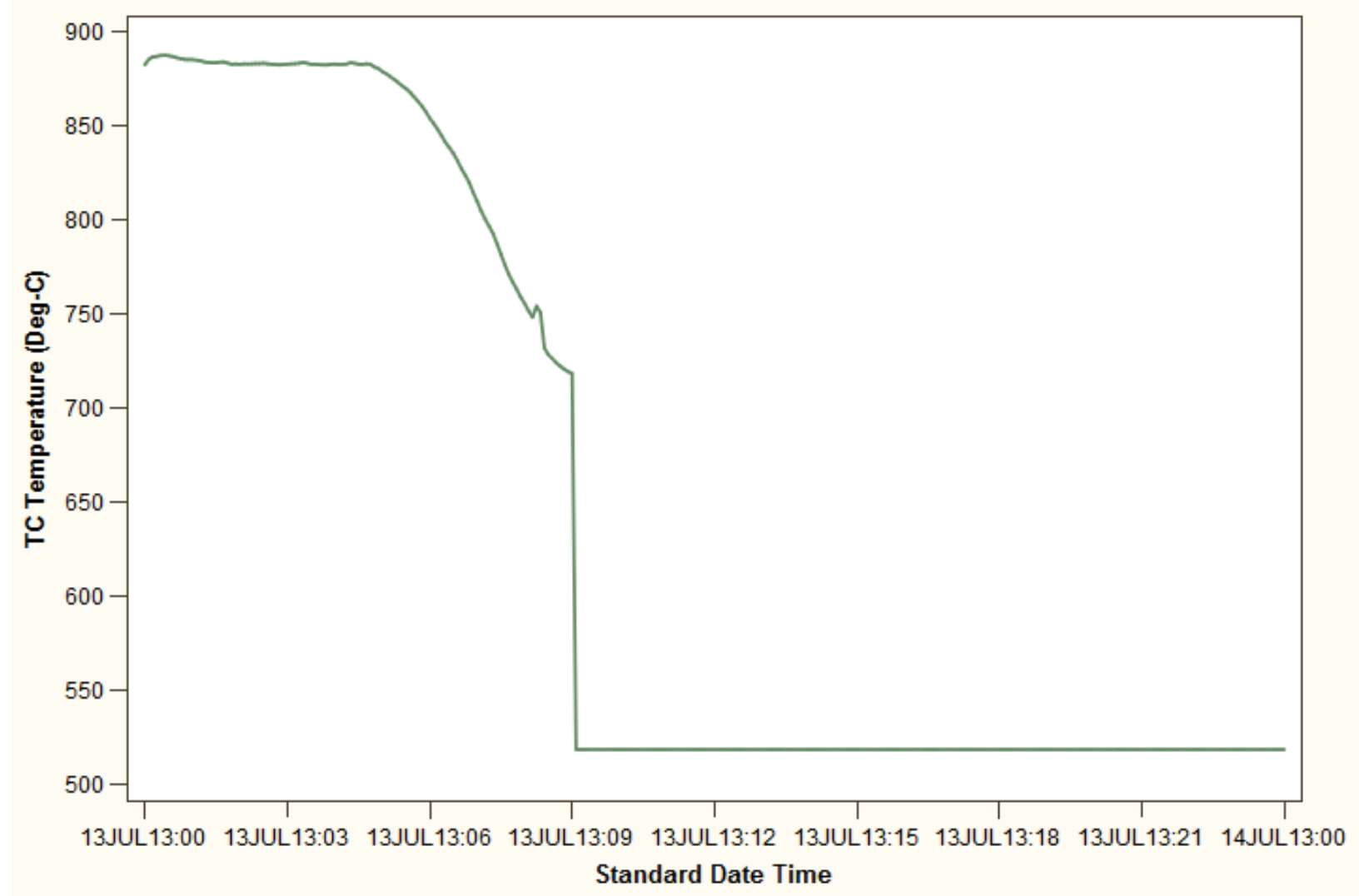

Figure 6. TC2 in Capsule 4 failed on 13 July 2013 at 9:00 after it stuck at $518.754^{\circ} \mathrm{C}$ when the ATR core was powering down to zero at the end of ATR Cycle 154A.

\subsubsection{Sweep Gas Data}

Figure 7 shows the hourly sweep gas flow rates averaged from instantaneous measurements for each capsule including helium inlet, neon inlet, total outlet, and newly added downstream meters at FPMS detector outlets (labeled "FPM"). Leadout gas flow (both helium and neon) are shown at the bottom panel of Figure 7 (same for all capsules). Gaps in gas flow plots represent periods with missing irradiation data during cycle outages. Fortunately, during that time AGR-2 ran on the same level of pure helium in all six capsules and the leadout. A discussion on gas flow rate anomalies as they relate to data qualification is presented in Section 3.2. 
AGR-2: Sweep Gas Flow Rates
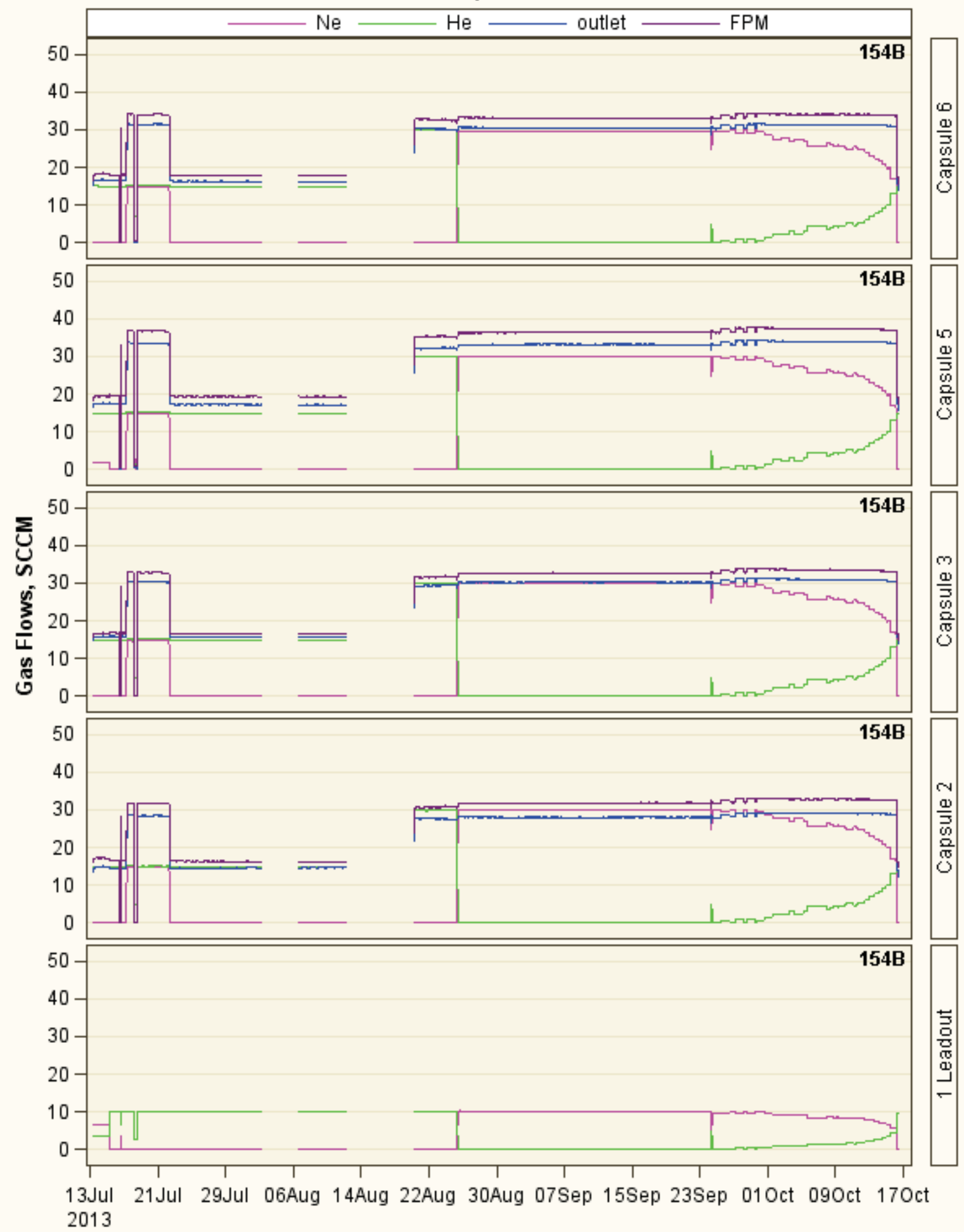

Figure 7. Capsule and leadout sweep gas flow rates (sccm). 


\subsubsection{FPMS Data}

Figure 8 and Figure 9 plot fission product release rate and R/B data (nominal 8-hour count times) in US capsules during the entire AGR-2 irradiation because of the revised R/B data calculated using the radionuclide daily birth rates as detailed in (ECAR-2420, 2014). This ECAR also provide the basis for FPMS data qualification. However, because of the cross-talk between capsule gas lines that began during ATR Cycle 150B, fission products from one capsule were suspected of entering other capsules' detectors. Therefore, the FPMS release rates are not representing the actual fission product in each capsule, so the subsequent FPMS data will not be qualified. However, the data still provide useful information for identifying particle failures and performing additional analyses and will be flagged as Trend.

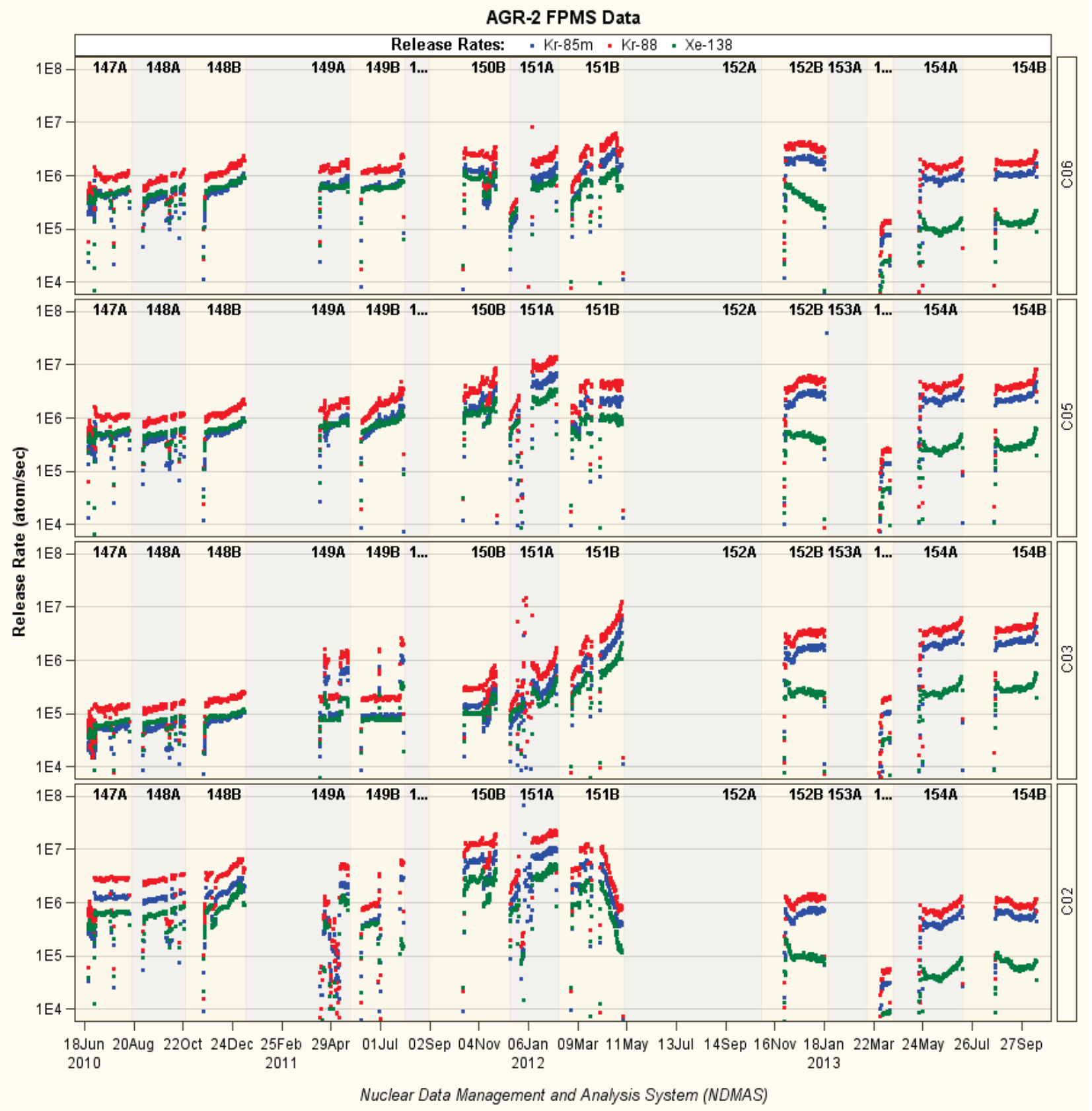

Figure 8. Fission product release rates for $\mathrm{Kr}-85 \mathrm{~m}, \mathrm{Kr}-88$, and $\mathrm{Xe}-138$ for all AGR-2 cycles, 147A through 154B. 


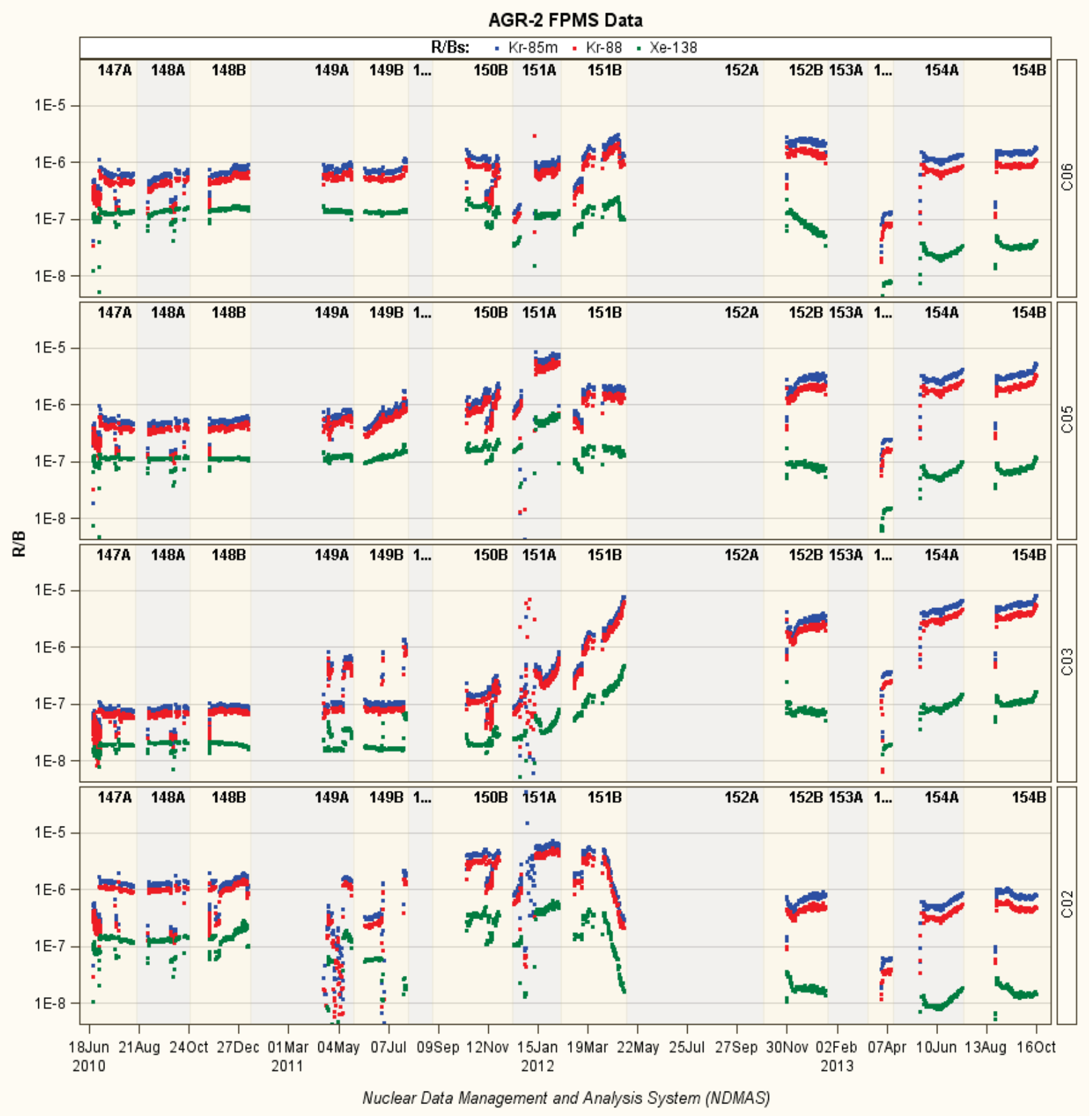

Figure 9. Fission product R/B ratios for Kr-85m, Kr-88, and Xe-138 for all AGR-2 cycles 147A through 154B.

\subsection{Testing for Data Anomalies of Gas Flow Rate Data}

This section discusses data anomalies of gas flow rates resulting from data testing and DRC data qualification decisions along with their impacts to program objectives. The three failure modes of gas flow rate measurements are: (1) missing, (2) out-of-range, and (3) failure to maintain the same neon fraction in all six capsules and leadout. Modes (1) and (2) are identified by range testing within the NDMAS data capture process. Mode (3) is identified by data analysis within the data qualification process. Details of the data failures are presented in the following subsections. 


\subsubsection{NDMAS Capture Range Testing}

In this section only neon, helium, and outlet flow data testing results are discussed. The FPM flow data are discussed separately in Section 3.2.3.

\subsubsection{Missing Data}

Data is classified as missing only if there is no record present for an existing time stamp in the raw data files provided by the data generators. There are no missing flow rates during ATR Cycle 154B.

\subsubsection{Out-of-Range Data}

Since the gas flow rates range from 0 to $102 \mathrm{sccm}$, the negative flow rates and "too high" flow rates $(>102 \mathrm{sccm})$ are usually assigned "failed" data status as a result of the NDMAS capture range testing. During ATR Cycle 154B, there are only 683 negative flow rates and zero "too high" flow rates out of a total of $2,365,720$ neon, helium, and outlet flow data records (or $0.03 \%$ of total records).

Negative Gas Flow Rates: All 683 negative flow rates are outlet flow rates in six capsules recorded on July 16, 2013 during an ATR Cycle 154B outage period. They are only slightly less than zero with their minimum value equal to $-0.0206 \mathrm{sccm}$ when the actual outlet flow rates were near zero. The negative flow rate values are well within measurement uncertainty bounds of $\pm 1 \mathrm{sccm}$, so they can be Qualified.

DRC recommendation: The 683 negative records of gas outlet flow rates are replaced with 0 sccm to avoid the use of negative gas flow values in calculations of other experimental parameters, such as fission product R/B ratios and set their quality status to Qualified.

\subsubsection{Testing for Failure to Maintain the Same Neon Fractions in Six Capsules and Leadout}

Significant capsule gas line crosstalk and leadout leakage problems that started to occur early in ATR Cycle 150B after the AGR-2 test was reinstalled back into the reactor following the ATR Powered Axial Locator Mechanism (PALM) Cycle 150A are still present during the cycle in this report. These cross-talk and leakage problems made it impossible to control the temperature in each capsule by independent gas mixtures as designed. So, AGR operational staff continued a procedure to set all capsules to the same helium/neon gas mixture ratio (neon fraction) for overall experiment temperature control. The following procedure was used to identify unreliable helium/neon inlet gas flow records (those that do not represent true individual capsule gas flow mixtures):

7. Capsule gas mixture data after the ATR PALM Cycle 150A are assumed to be valid only when the gas flow mixture ratio (e.g., neon fraction) was approximately the same between all capsules (and the leadout). This operating procedure was fully implemented on January 17 , 2012, in mid-ATR Cycle 151A.

8. When the neon fraction for a given capsule was not approximately the same as all other capsules, the helium/neon inlet records for all capsules for that time step were considered to be unreliable. These unreliable records were identified by: (1) calculating the mean neon fraction of all capsules for each time step (5-min data records); and (2) identifying those records where the ratio of the maximum capsule neon fraction to mean neon fraction for a given time step was greater than 0.08 .

The DRC approved the above procedure during qualification of data from the previous cycles. According to Figure 10, the neon fractions in all six capsules and the leadout were maintained uniform for the entire ATR Cycle 154B. Additionally, there is no indication of flow meter failure during this time, so the inlet neon and helium flow rates are qualified and the neon fractions calculated as fraction of inlet neon/helium flow rates for all capsules are the actual neon fractions to be used in the capsule thermal models. 
The DRC also decided that all capsule outlet flow (Q_Mix_Out) data received after ATR Cycle 150A may have capsule cross-talk; therefore, the data are not reliable for their intended use in determining FPMS release rates and R/Bs. However, all of the capsule outlet gas flow rates records for ATR Cycle $154 \mathrm{~B}$ are still qualified to be used for other purposes because there is no indication of flow meter failure.

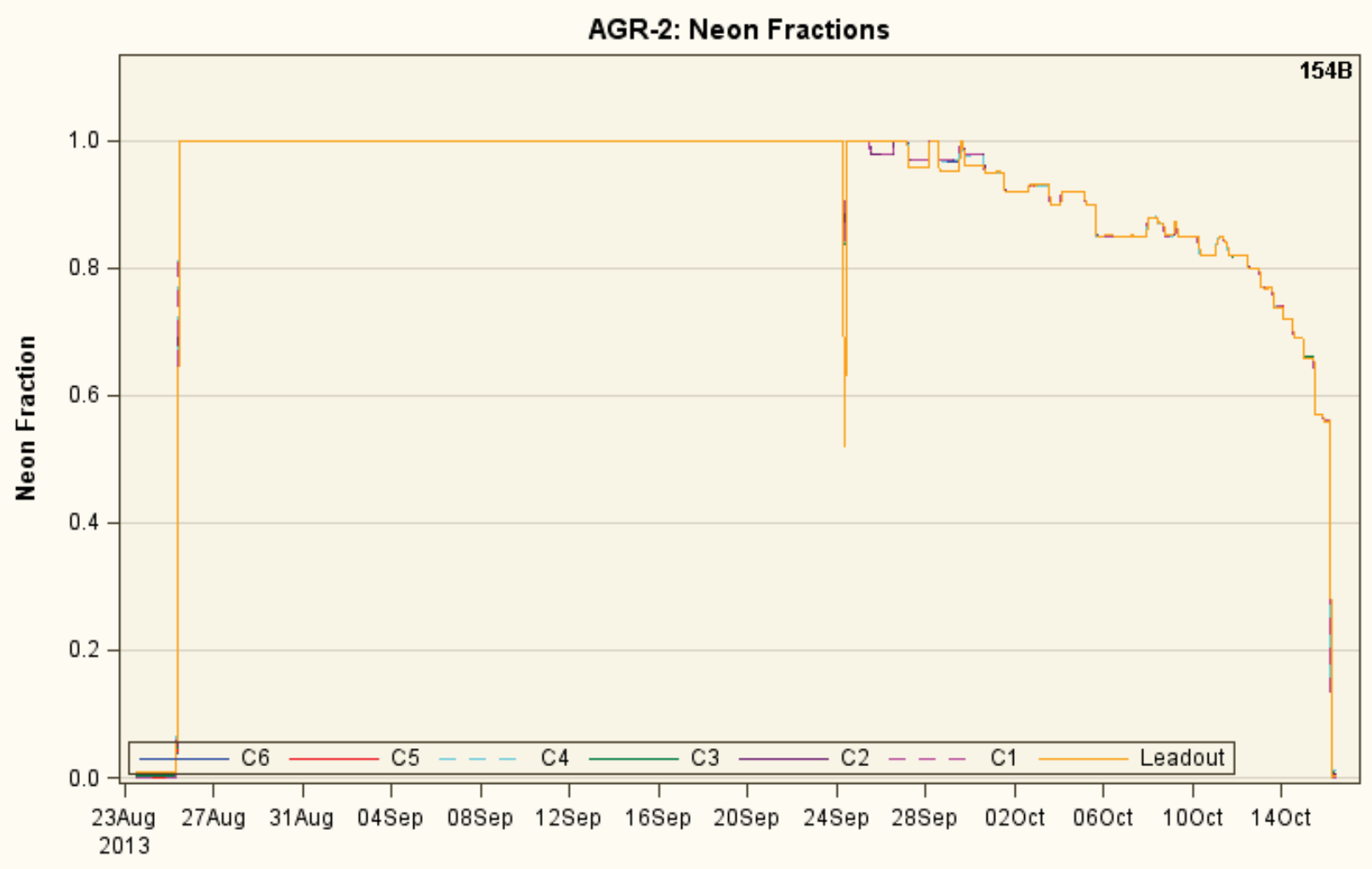

Nuclear Data Management and Analysis System (NDMAS)

Figure 10. Capsule neon fractions for Cycle 154B.

\subsubsection{Downstream Gas Flow Data Failures}

The outlet lines transport mixed gas together with any fission products released from the capsules to the FPMS, which is capable of detecting individual fuel particle failures. A relief valve was installed before each detector to maintain required gas pressure in each capsule. If this valve lifts, then the mixed gas will leak out before reaching the detector, thus preventing it from correctly counting the release rate from the capsule. To detect and prevent valve lifting, seven additional gas flow meters were installed at the outlets of the seven FPMS detectors to measure downstream gas flow rates (labeled by FPM) from these detectors during ATR Cycle 153A. The first record of FPM flow data received by NDMAS was on February 26, 2013 at 10:40. Ideally, the downstream gas flow rates should be similar to the outlet flow rates measured at the capsule outlets when the relief valves are tight allowing all mixed gas from the capsules to flow to their corresponding FPMS detectors. This feature will be used to assess quality of the downstream data. Figure 11 shows hourly averaged flow rates of downstream (purple line) and outlet (blue line) flows for AGR-2 US capsules from the time when the downstream data were first captured in the NDMAS database. Apparently, the FPM flow rates are consistently higher than the outlet flow rates in all capsules indicating measurement biases by 3 to $5 \mathrm{sccm}$ of the downstream flow meters.

DRC recommendation: flag all FPM flow rates during Cycle 154B as Trend data due to measurement biases. 


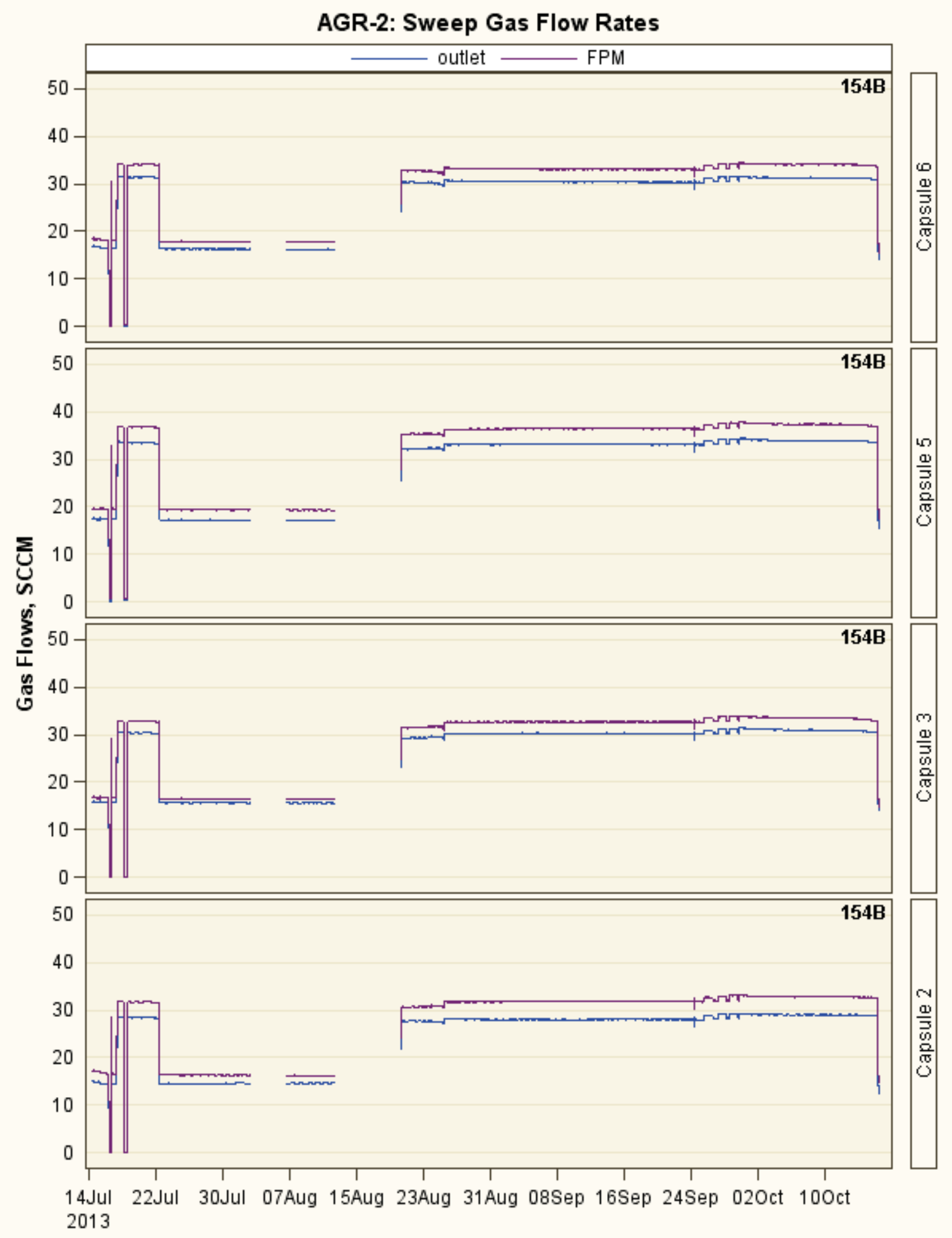

Figure 11. Downstream and outlet gas flow rates for AGR-2 U.S. capsules 


\subsection{Repair AGR-2 Gas Flow Data in NDMAS Database}

As the result of AGR-2 data testing and analysis, there are many gas flow rate records classified as Failed due to missing, negative, and stuck values. The majority of these failures occurred during the ATR outage periods, when the impact of bad flow data is not critical to the test objectives. However, some of those Failed flow records occurred when the ATR was at full power, preventing exact determination of the neon fractions for the capsules. The neon fractions are crucial inputs to the capsule thermal models used for fuel temperature calculation. Therefore, an effort was made to repair the Failed flow data, especially during ATR full power periods.

The automated data output script occasionally generates stuck or missing gas flow rates when flow rates are near zero. In order to correct those erroneous data, the additional AGR irradiation data from the CDCS historian, which collects and stores the capsule irradiation data, were received. These data file are used as reference for the repair of stuck and missing data on top of the data inconsistency revealed by data analysis. Three files stored in NDMAS folder

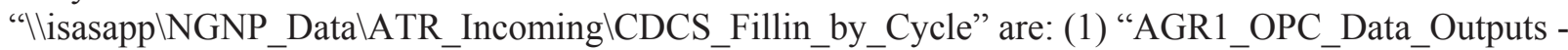
2012Nov270000 to 2012Dec102100@1 Min.csv” for ATR Cycle 152B, (2)

“AGR1_OPC_Data_Outputs - 2013Apr16 1000 to 2013May24 $0700 @ 1$ Min.csv” for ATR Cycle 154A, and (3) "AGR1_OPC_Data_Outputs - 2013Jul22 0800 to 2013Aug20 0000 @1 Min.csv” for ATR Cycle 154B.

\subsubsection{Replace Stuck Neon Flow Rates in Capsule 1}

Figure 12 shows neon flow rates in Capsules 1, 2, 3, 5, and 6 during ATR Cycles 154A and 154B. Notably, the neon flow rates in all capsules except Capsule 1 are following each other perfectly. This is by design because the gas mixture is maintained at the same level for all capsules due to cross-talk between their gas lines. Several occasions were identified when neon flow rates in Capsules 2, 3, 5, and 6 are at zero level, but the neon flow rates in Capsule 1 (bottom panel of Figure 12) are stuck at higher values (more than $10 \mathrm{sccm}$ ). These periods are highlighted with the dark blue rectangles. Neon flow rates in Capsule 1 would have been approximately the same as all the other capsules during these periods. Therefore, periods of elevated Neon gas flow rate in Capsule 1, identified by the blue rectangles, were estimated using the neon gas flow rates of Capsule 2, which were near zero as they should be. The specific time intervals are: (1) April 16, 2013 08:44:00 to May 20, 2013 11:17:01 (ATR Cycle 154A), (2) May 21, 2013 04:18:01 to May 25 (ATR Cycle 154A), 2013 06:08:01, and (3) July 22, 2013 08:47:39 to August 18, 2013 00:00:00 (ATR Cycle 154B).

These neon flow rate corrections in Capsule 1 were supported by the additional data in the following files: (1) “AGR1_OPC_Data_Outputs - 2013Apr16 1000 to 2013May24 0700 @1 Min.csv” for ATR Cycle 154A and (2) “AGR1_OPC_Data_Outputs - 2013Jul220800 to 2013Aug20 0000 @1 Min.csv” for ATR Cycle 154B. 


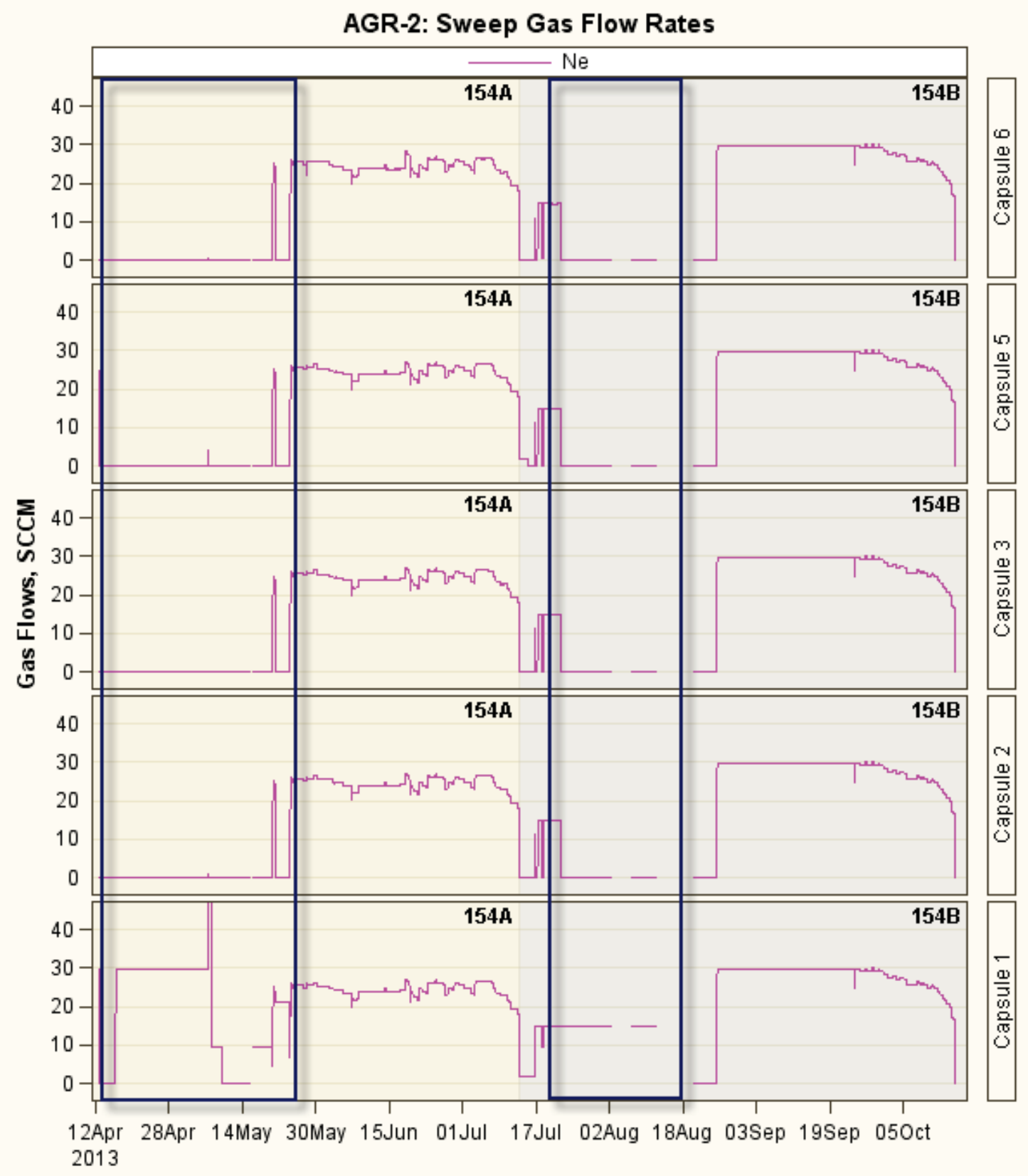

Figure 12. Capsule neon flow rates for ATR Cycles 154A and 154B showing the periods (within rectangles) when neon flow to Capsule 1 was reported erroneously due to a programming error in the automated data output script.

\subsubsection{Replace Negative Gas Flow Rates with Zero}

During the AGR-2 experiment, there were 7,846 records where gas flow was between -0.1 and 0.0 $\mathrm{sccm}$. These very small negative values are all within the uncertainty of the flow meter, and reflect no gas flow through the meter. The 7,846 negative gas flows were replaced with $0 \mathrm{sccm}$ to avoid the use of negative gas flow values in calculations of other experimental parameters, such as fission product R/B ratios. 


\subsubsection{Fill-in Missing Neon Flow Rates in Capsule 1 and Leadout}

A number of neon gas flow values are missing during ATR Cycle 152B. Missing neon gas flow periods are shown in Figure 13, identified with rectangles: for Capsule 1 prior to power-up for Cycle 152B, and for leadout in the early days of ATR Cycle 152B. All capsules were being fed the same gas mixtures because of capsule cross-talk issues, so the missing neon gas flow data for Capsule 1 can be estimated using the gas flow from the adjacent Capsule 2. Missing neon gas flow rates to Capsule 1 for the periods Nov 27, 2013 12:00 to Nov 29, 2013 22:35 were replaced with near-zero neon gas flow rates from Capsule 2. The missing leadout data cannot be estimated from the other capsules, because no neon was being fed through leadout early in ATR Cycle 152B. Therefore, the missing leadout neon values were estimated to be $0 \mathrm{sccm}$ during the period Nov 30, 2012 00:45 to Dec 10, 2012 17:17:02. These fillin neon flow rates were confirmed by the additional data in the file "AGR1_OPC_Data_Outputs 2012Nov270000 to 2012Dec102100@1 Min.csv” for ATR Cycle 152B.

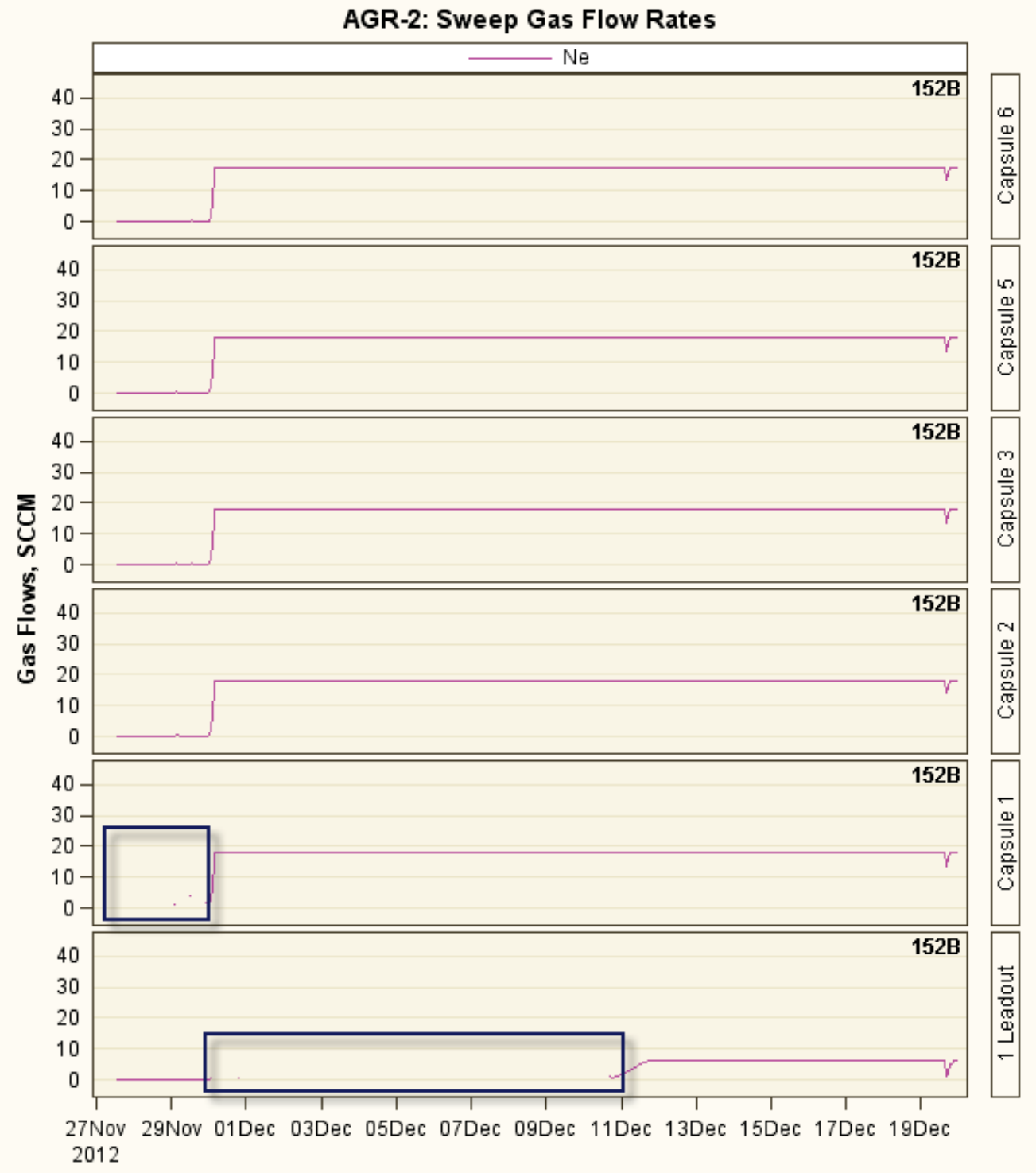

Figure 13. Neon gas flow rates in AGR-2 after power-up for ATR Cycle 152B. Periods of missing gas flow data for Capsule 1 and leadout are identified with rectangles. 


\section{DATA RECORD QUALIFICATION SUMMARY}

This section summarizes the data qualification decisions made by the DRC for the data packages received by NDMAS from July 13 through October 16, 2013 (Cycle 154B). Detailed information on the data and the technical basis for data record qualification can be found in Sections 2 and 3.

\subsection{Irradiation Monitoring Data}

AGR irradiation monitoring data captured in the NDMAS database are 1-minute instantaneous measurements for this cycle. The new data delivery method provides NDMAS with significantly more irradiation data and therefore requires implementation of a more flexible data structure and online database testing.

\subsubsection{NDMAS Testing Results}

As the increased amount of irradiation data delivered and automatically processed every hour into the NDMAS database the automatic online testing procedure described in Section 2.3.3 was implemented for all AGR irradiation data streams. There are no Failed gas pressure or moisture measurements. Therefore, results of the database testing presented in the following subsections are only for TC readings and gas flow measurements.

\subsubsection{TC Readings}

The last AGR-2 TC failed right at the end of ATR Cycle 154A, therefore all 1,774,290 records of TC data for this reporting period are counted as Failed records due to instrument failures.

\subsubsection{Sweep Gas Data}

Table 6 summarizes qualification status of gas flow records resulted from the NDMAS database testing for neon helium, outlet, and FPM flow rates during ATR Cycle 154B. There are 683 negative outlet flow rates recorded on July 16, 2013 during the ATR Cycle 154B outage period. They are only slightly less than zero with their minimum value equal $-0.0206 \mathrm{sccm}$ when the actual outlet flow rates were near zero; therefore, the records are Qualified and replaced with zero in the database as described in Section 3.3.2. The DRC members agreed (via email correspondence) with the decisions on data qualification of gas flow rates during ATR Cycle 154B as: (1) 2,365,720 capsule flow rate records flagged as Qualified (100\% of the capsule flow data) and (2) 828,002 FPM flow rates during ATR Cycle 154B flagged as Trend (100\% of the FPM flow data).

As a result, a total of 3,193,722 1-minute sweep gas flow rates were recorded for the ATR Cycle $154 \mathrm{~B}$ evaluated in this report. Of these data, 2,365,720 capsule flow rate records met the requirements for Qualified data (74.07\% of the total) and 828,002 FPM flow rates were Trend data (25.93\% of the total).

Table 6. Gas flow data qualification summary for ATR Cycle 154B

\begin{tabular}{|ccccccc|}
\hline $\begin{array}{c}\text { ATR } \\
\text { Cycle }\end{array}$ & $\begin{array}{c}\text { Total \# } \\
\text { Records }\end{array}$ & \# of Failed & $\begin{array}{c}\text { \# of Trend } \\
\text { (FPM) }\end{array}$ & \% Failed & \% Trend & \% Qualified \\
\hline 154B & $3,193,722$ & 0 & 828,002 & $0 \%$ & $25.93 \%$ & $74.07 \%$ \\
\hline
\end{tabular}

\subsubsection{Data Qualification Summary}

NDMAS received a total of 4,968,012 instantaneous (taken every minute) irradiation monitoring data records for the ATR Cycle 154B evaluated in this report (Table 7). Of these data, $47.62 \%$ met the requirements for Qualified data, 35.71\% were Failed data, and $16.67 \%$ were Trend data (FPM flow data during ATR Cycle 154B). There were 1,774,290 TC records (100\% of the total) that were Failed because 
of TC instrument failure. But there were zero helium/neon inlet and outlet gas flow records that were Failed. For FPM flow rates, there are 828,002 Trend records during ATR Cycle 154B. All of the pressure and moisture (humidity) sweep gas data were classified as Qualified by the DRC.

Table 7. Summary of the qualification status of the irradiation monitoring data (TC temperature and sweep gas) received by NDMAS during ATR Cycle 154B.

\begin{tabular}{|c|c|c|c|c|c|c|c|c|c|}
\hline \multirow[b]{2}{*}{$\begin{array}{l}\text { ATR } \\
\text { Cycle }\end{array}$} & \multirow[b]{2}{*}{$\begin{array}{l}\text { Record } \\
\text { Start }\end{array}$} & \multirow[b]{2}{*}{$\begin{array}{l}\text { Record } \\
\text { End }\end{array}$} & \multirow[b]{2}{*}{$\begin{array}{c}\text { Total \# } \\
\text { Records }\end{array}$} & \multicolumn{2}{|c|}{ No. of Failed Records } & \multirow[b]{2}{*}{$\begin{array}{l}\text { FPM } \\
\text { Trend }\end{array}$} & \multirow[b]{2}{*}{$\%$ Failed } & \multirow[b]{2}{*}{$\%$ Trend } & \multirow[b]{2}{*}{$\begin{array}{c}\% \\
\text { Qualified }^{(b)}\end{array}$} \\
\hline & & & & $\mathrm{TC}^{(\mathrm{a})}$ & Gas Flow & & & & \\
\hline & & & $4,968,01$ & $1,774,29$ & & 828,00 & & & \\
\hline $154 \mathrm{~B}$ & 13JUL13 & $16 \mathrm{OCT} 13$ & 2 & 0 & 0 & 2 & $35.71 \%$ & $16.67 \%$ & $47,62 \%$ \\
\hline
\end{tabular}

\subsection{FPMS Data}

As of this report publication, NDMAS has received and processed into its database preliminary release rate and R/B data for ATR Cycle 154B (see Figure 8 and Figure 9). This consists of 12,372 (nominal 8-hour) release rate records and 12,372 R/B records for 12 reported radionuclides $(\mathrm{Kr}-85 \mathrm{~m}, \mathrm{Kr}$ 87, Kr-88, Kr-89, Kr-90, Xe-131m, Xe-133, Xe-135, Xe-135m, Xe-137, Xe-138, and Xe-139). All of these data have been capture passed, stored in the NDMAS database, and made available on the NDMAS Web portal (see Figure 8 and Figure 9). Due to the capsule flow cross-talk issues that began during ATR Cycle 150B, the subsequent FPMS data will not be qualified. However, the data still provide useful information for identifying particle failures and performing additional analyses and they will be flagged as Trend. The qualification status of these data has been set to In Process until appropriate documentation is received from the data generator.

\section{DATA ACCESS}

The irradiation monitoring data and data qualification statuses are available on the NDMAS Web portal (http://ndmas.inl.gov) for secure access by VHTR TDO program participants as shown in Figure 14 for the external website. The website is organized by experiment (e.g., AGR-2) and data stream (e.g., IRR for irradiation data). These Web pages (blue bar on left in Figure 14) have multiple portlets with different data type content, including plots and tabular data that can be interactively queried (e.g., sorted or filtered by capsule or date) or expanded ("drill-down") by date. The tabular data (_DATA reports below) can be downloaded to a .csv file or opened directly in Excel. 
Preliminary

- NDMAS Home

† AGC-1

(4) AGC-2

4) AGR-1

AGR-2

FAB

FPM

GG

IRR

4. Analysis

Qualification

(4) AGR-3/4

$\oplus$ High Temp Mat

Qualification

Contacts

Help

\section{(1)}

\section{AGR-2 Irradiation Monitoring Data}

The report links on this page provide interactive displays of the irradiation monitoring data for the AGR-2 experiment. Data include reactor power $(\mathrm{MW})$, helium and neon flow rates $(\mathrm{sccm})$ through the capsules, capsule thermocouple temperatures (degrees C), and fission product release-to-birth rate (R/B) ratios (currently provided after reactor cycle shutdown). Two types of reports are provided - "Individual Cycles" reports that show single reactor cycle data for all capsules and "All Cycles" reports that show individual capsule data over all reactor cycles. Note: All hourly values are in Mountain Standard Time (MST).

For viewing plots of the data, select the "_PLOTS" reports. Users may "drill-down" to view hourly values for a given day by right clicking any daily value on the x-axis. To return to daily values, right click the "Hour (MST)" axis label.

For downloading data, select the "_DATA" reports. To download, right click within the red table border, select "Export Table...", and save the file as a comma separated values (.csv) file. Opening a .csv file with Excel will require conversion of text to columns using a comma delimiter.

All data are currently preliminary, and data qualification is in process.

AGR-2/IRR point-of-contact: Mitch Plummer, (208) 526-2785

AGR-2/IRR Web Page point-of-contact: Mike Abbott, (208) 526-8596

AGR-2 Individual Cycles_PLOTS

AGR2 Cycle 147A All Capsules_PLOTS.srx [AGR2/IRR/AGR2 Cycle 147A All Capsules_PLOTS.srx: v2.00]

AGR2 Cycle 148A All Capsules_PLOTS.srx [AGR2/IRR/AGR2 Cycle 148A All Capsules_PLOTS.srx: v2.00]

AGR2 Cycle 148B All Capsules_PLOTS.srx [AGR2/IRR/AGR2 Cycle 148B All Capsules_PLOTS.srx: v2.00]

AGR2 Cycle 149A All Capsules_PLOTS.srx [AGR2/IRR/AGR2 Cycle 149A All Capsules_PLOTS.srx: v2.00]

AGR2 Cycle 149B All Capsules_PLOTS.srx [AGR2/IRR/AGR2 Cycle 149B All Capsules_PLOTS.srx: v2.00]

FigR2 Cycle 150B All Capsules_PLOTS.srx [AGR2/IRR/AGR2 Cycle 150B All Capsules_PLOTS.srx: v2.00]

AGR2 Cycle 151A All Capsules_PLOTS.srx [AGR2/IRR/AGR2 Cycle 151A All Capsules_PLOTS.srx: v2.00]

AGR2 Cycle 151B All Capsules_PLOTS.srx [AGR2/IRR/AGR2 Cycle 151B All Capsules_PLOTS.srx: v2.00]
AGR-2 Individual Cycles_DATA

AGR2 Cycle 147A All Capsules_DATA.srx [AGR2/IRR/AGR2 Cycle 148A All Capsules_DATA.srx: v2.00]

AGR2 Cycle 148A All Capsules_DATA.srx [AGR2/IRR/AGR2 Cycle 148A All Capsules_DATA.srx: v2.00]

AGR2 Cycle 148B All Capsules_DATA.srx [AGR2/IRR/AGR2 Cycle 148A All Capsules_DATA.srx: v2.00]

19. AGR2 Cycle 149A All Capsules_DATA.srx [AGR2/IRR/AGR2 Cycle 149A All Capsules_DATA.srx: v2.00]

AGR2 Cycle 149B All Capsules_DATA.srx [AGR2/IRR/AGR2 Cycle 149B All Capsules_DATA.srx: v2.00]

FigR2 Cycle 150B All Capsules_DATA.srx [AGR2/IRR/AGR2 Cycle 150B All Capsules_DATA.srx: v2.00]

AGR2 Cycle 151A All Capsules_DATA.srx [AGR2/IRR/AGR2 Cycle 151A All Capsules_DATA.srx: v2.00]

AGR2 Cycle 151B All Capsules_DATA.srx [AGR2/IRR/AGR2 Cycle 151B All Capsules_DATA.srx: v2.00]

Figure 14. The AGR-2 Web page (in blue bar on left) on the external NDMAS Web portal provides access to numerous types of data reports, graphs, and images. 


\section{REFERENCES}

Abbott, M. L. and Pham, B.T., "AGR-2 Data Qualification Report for ATR Cycles 149B, 150A, 150B, 151A, and 151B, INL/EXT-12-26184," Idaho National Laboratory, 2012.

Abbott, M. L. and Pham, B.T., "AGR-2 Data Qualification Report for ATR Cycles 147A, 148A, 148B, and 149A," INL/EXT-11-22798, Idaho National Laboratory, 2011.

ASME NQA-1, "Quality Assurance Requirements for Nuclear Facility Applications.” 2008, 1A 2009 addenda.

FRM-1073, “Data Evaluation Report,” Ref. 1, Idaho National Laboratory, June 13, 2011.

GDE-503, “Users' Guide for the Fission Product Monitoring System," Rev. 0, Idaho National Laboratory.

Hull, L., "NDMAS System and Process Description," INL/EXT-12-27594, Idaho National Laboratory, Idaho Falls, ID, February, 2012.

IAS121679, "Review of INL QA Program Execution for NDMAS ATR Data Source Streams," Idaho National Laboratory, 2012.

MCP-2691, “Data Qualification,” Rev. 1, Idaho National Laboratory, Idaho Falls, ID, June 13, 2011.

MCP-3058, "VHTR TDO Software Quality Assurance,” Rev. 1, Idaho National Laboratory, 2012.

PDD-13000, “Quality Assurance Program Description,” Rev. 2, Idaho National Laboratory, 2008.

Pham, B.T. and Einerson, J.J., "AGR-2 Data Qualification Report for ATR Cycles 151B-2, 152A, 152B, 153A, 153B, and 154A,” INL/EXT-13-29701, Idaho National Laboratory, 2013.

PLN-2690, "VHTR Technology Development Office Quality Assurance Program Plan," Rev. 8, Idaho National Laboratory, July 28, 2011.

PLN-2709, "Very-High-Temperature-Reactor Program Data Management and Analysis Plan," Rev. 3, Idaho National Laboratory, July 11, 2011.

PLN-3319, "Records Management Plan for the VHTR Technology Development Office Program," Rev. 2, Idaho National Laboratory, May 16, 2012.

PLN-3551, "Fission Product Monitoring System Operability Test Plan for the AGR Experiment Series," Rev. 1, Idaho National Laboratory, Idaho Falls, ID, November 29, 2011.

PLN-3636, "Technical Program Plan for the Next Generation Nuclear Plant/Advanced Gas Reactor Fuel Development and Qualification Program," Rev. 2, Idaho National Laboratory, December 18, 2012.

PLN-3798, “AGR-2 Irradiation Experiment Test Plan,” Rev. 1, Idaho National Laboratory, October 5, 2011.

Scates, D.M., Release-To-Birth Ratios FRO AGR-2 Operating Cycles 147A - 154B, ECAR-2420, 2014.

SPC-1064, "AGR-2 Irradiation Test Specification," Rev. 1, Idaho National Laboratory, June 1, 2011.

TFR-248, "Temperature Control and Off Gas Monitoring Systems for Advanced Gas Reactor Experiment AGR-1," Rev. 4, Idaho National Laboratory, December 23, 2010.

TFR-559, "Requirements for the Design of the Advanced Gas Reactor Experiment AGR-2 for Irradiation in the ATR," Rev. 2, Idaho National Laboratory, April 22, 2010.

TFR-747, "RDAS-CDCS Data Transfer to NDMAS," Rev. 3, Idaho National Laboratory, March 11, 2013. 


\section{Appendix A}

\section{Credentials of Technical Reviewer}




\section{Appendix A}

\section{Credentials of Technical Reviewer}

\section{Credentials for Blaise Collin}

Blaise Collin is a senior nuclear physicist and engineer with more than 10 years of experience in modeling, simulation, and data analysis. His past fields of interest and expertise include intermediate energy nuclear physics, particle astrophysics, neutronics and nuclear reactor core physics. His current focus is on the modeling and assessment of TRISO fuel performance, especially for its use in the AGR experiments. In his different activities, he performed experimental modeling, ran simulations, and analyzed the subsequent results and output data. As a member of the AGR Fuel Development and

Qualification Program team, he has a sound knowledge of the AGR-2 experiment, of which he wrote the Irradiation Experiment Test Plan. 